\title{
Tests of the Motor Neuron Model of the Local Pattern-Generating Circuits in the Swimmeret System
}

\author{
Carolyn M. Sherff and Brian Mulloney \\ Section of Neurobiology, Physiology, and Behavior, Division of Biological Sciences, University of California, Davis, \\ California 95616-8755
}

The motor pattern that drives each crayfish swimmeret consists of alternating bursts of impulses in power-stroke (PS) and return-stroke (RS) motor neurons. A model of the neural circuit that generates this pattern focused on connections between motor neurons themselves (Heitler, 1978, 1981). The model predicts that synergist motor neurons are electrically coupled, whereas antagonists make mostly inhibitory synapses. We tested this model by observing the responses of motor neurons to pressure ejection of GABA and glutamate, transmitters that crayfish motor neurons release at neuromuscular junctions, and by measuring the strengths and delays of synapses between pairs of motor neurons. Both GABA and glutamate inhibited motor neurons. This inhibition persisted when synaptic transmitter release was blocked by high $\mathrm{Mg}^{2+}$. The effects of GABA were mimicked by muscimol, but not by baclofen or the $\mathrm{GABA}_{\mathrm{C}}$ receptor agonist cis-4-aminocrotonic acid, and they were not blocked by bicuculline. The effects of glutamate were mimicked by ibotenic acid. Picrotoxin partially blocked glutamate's inhibition of the motor pattern, but did not affect GABA responses. Most (87\%) pairs of synergist motor neurons tested made weak, noninverting connections. Approximately half of these had synaptic delays of $<2 \mathrm{msec}$, consistent with direct electrical or chemical synapses. Individual motor neurons were dyecoupled to between one and three other motor neurons, and to interneurons. Less than half (44\%) of the pairs of antagonist motor neurons tested made synaptic connections. These connections were weak, had long latencies (>4 msec), and therefore were probably polysynaptic. We conclude that direct synapses between swimmeret motor neurons cannot account for alternation of PS and RS bursts.

Key words: crustacea; swimmeret; motor pattern; synaptic inhibition; neural circuits; electrical synapses; GABA; glutamate; chloride current; motor neurons; muscimol; ibotenic acid; picrotoxin
When crayfish swim forward, four pairs of swimmerets move rhythmically with alternating power-stroke (PS) and return-stroke (RS) movements driven by alternating bursts of action potentials in excitatory PS and RS motor neurons (PSE and RSE) (Fig. 1). Each swimmeret is innervated by $\sim 30$ PSE and 30 RSE motor neurons (Mulloney et al., 1990) that release glutamate at their neuromuscular junctions (Takeuchi and Takeuchi, 1964; Onodera and Takeuchi, 1975, 1976; Dekin, 1983). Each swimmeret also has five peripheral inhibitory motor neurons, two PSI and three RSI (Mulloney and Hall, 1990), that release GABA (Dudel et al., 1963; Kravitz et al., 1963a,b; Takeuchi and Takeuchi, 1965) and may fire bursts of impulses that alternate with those of excitors to the same muscles (e.g., RSI in Fig. 1). How are the alternating firing patterns of these four functional groups of motor neurons (PSE, RSE, PSI, and RSI) determined?

Each swimmeret has its own pattern-generating circuit (Mulloney et al., 1993; Murchison et al., 1993). From observations that currents injected into one motor neuron sometimes affected other motor neurons and even reset the timing of the entire motor pattern, a model was proposed in which central synapses between motor neurons caused PS-RS alternation (Heitler, 1978, 1981, 1983; Heitler and Mulloney, 1978). In this model (Fig. 2), motor neurons with antagonistic functions inhibit each other through

\footnotetext{
Received July 14, 1995; revised Jan. 16, 1996; accepted Jan. 22, 1996.

This work was supported by National Science Foundation Grants BNS 87-19397 and IBN 92-22470. We thank professors Andrew Ishida and Karen Sigvardt for critically reading drafts of this manuscript.

Correspondence should be addressed to Carolyn M. Sherff, Department of Psychology, Yale University, New Haven, CT 06520-8205.

Copyright $\odot 1996$ Society for Neuroscience $0270-6474 / 96 / 162839-21 \$ 05.00 / 0$
}

direct chemical synapses. Motor neurons with synergist functions, including motor neurons within a functional group, such as PSEs or RSEs, and motor ncurons in different syncrgist groups, such as PSE and RSI, are electrically coupled.

This model proposed a specific synaptic organization of these motor neurons, but the experiments on which the model was based did not permit a quantitative description of these synapses or an evaluation of their importance in generating the motor pattern relative to synapses between motor neurons and local interneurons (Heitler and Pearson, 1980; Paul and Mulloney, 1985a,b). The experiments reported here tested several predictions of this model.

The model predicts that excitatory motor ncurons release glutamate at their inhibitory central chemical synapses, that inhibitory motor neurons release GABA, and that both transmitters will inhibit swimmeret motor neurons directly. As predicted, pressure ejection of either GABA or glutamate inhibited swimmeret motor neurons by decreasing their input resistances and usually hyperpolarizing their membrane potentials. These inhibitory actions were mimicked by muscimol and ibotenic acid.

The model also predicts that connections between swimmeret motor neurons would be monosynaptic and that these synapses would be strong enough to influence the entire motor pattern. Many synergist motor neurons proved to be electrically coupled, and some antagonist motor neurons were functionally connected by inhibitory pathways. However, these inhibitory interactions were weak, uncommon, and had synaptic delays too long for monosynaptic connections. It is unlikely that these inhibitory connections cause the observed alternation of bursts of impulses in PS and RS motor neurons. 


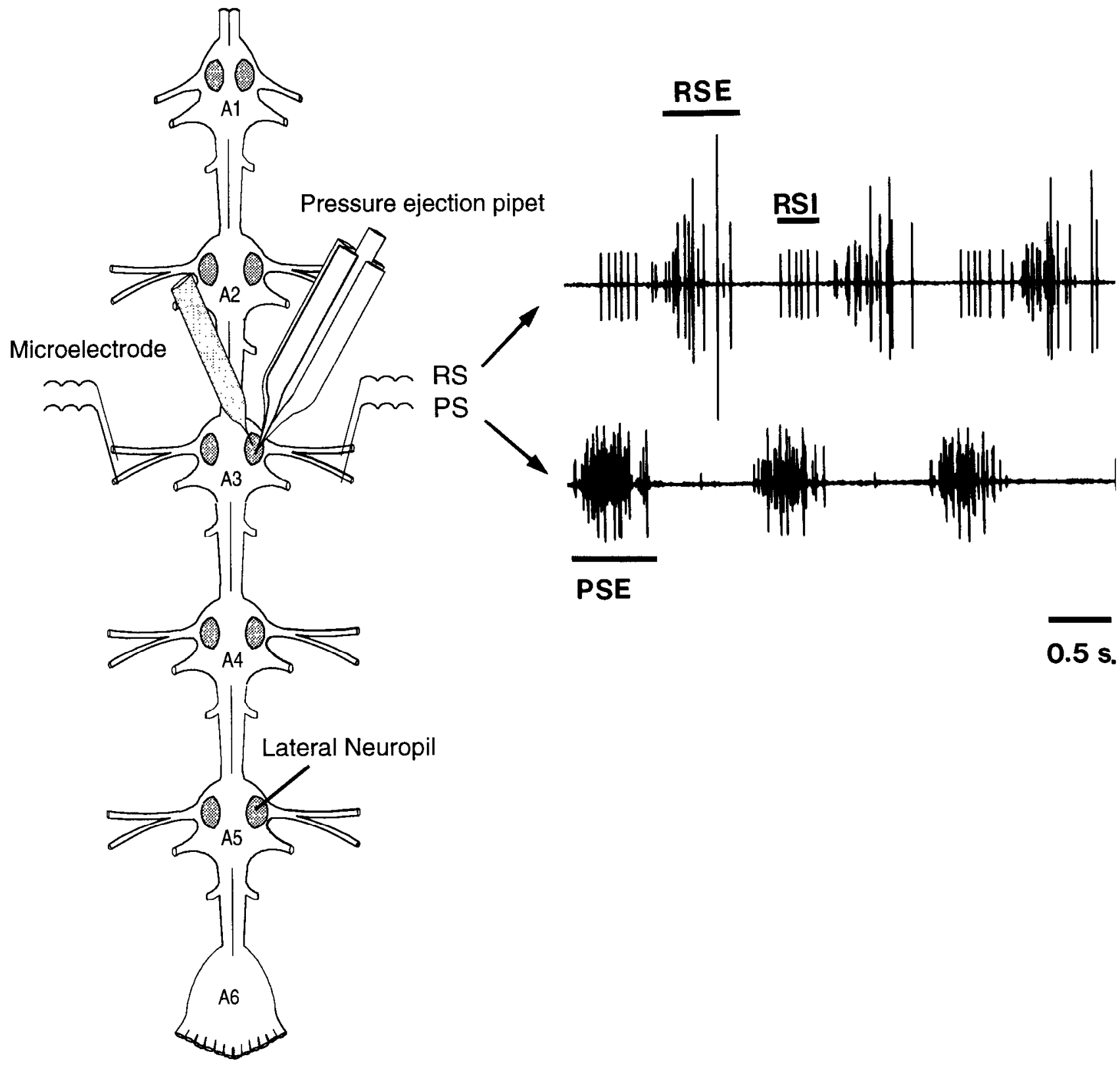

Figure 1. The preparation included six abdominal ganglia $(A 1-A 6)$. Intracellular recordings were usually made from processes of a motor neuron in the lateral neuropil (shaded areas) of $A 3$. Simultaneous extracellular recordings were made from the RS and PS branches of both N1s; a sample of these recordings is shown on the right. GABA, glutamate, and other drugs could be pressure-ejected through a multibarreled micropipette inserted into the same neuropil. PSE, Power-stroke excitors; RSE, return-stroke excitors; RSI, return-stroke inhibitor.

\section{MATERIALS AND METHODS}

Animals. Crayfish, Pacifastacus leniusculus, were obtained from local fishermen and kept in aerated, freshwater aquaria. Animals were anesthetized by chilling them on ice. They were then exsanguinated by perfusing physiological saline that contained (in $\mathrm{mm}$ ) $5.4 \mathrm{KCl}, 2.6$ $\mathrm{MgCl}_{2}, 13.5 \mathrm{CaCl}_{2}, 195 \mathrm{NaCl}$, buffered with $10 \mathrm{mM}$ Tris maleate, $\mathrm{pH} 7.4$ (Mulloney and Hall, 1990, adapted from van Harreveld, 1936), into a wound created by removing one of the claws. The portion of the ventral nerve cord containing the two posterior thoracic ganglia and all six abdominal ganglia was removed and pinned dorsal side up with its attached swimmeret nerves (N1) in a dish lined with Sylgard (Dow Corning, San Francisco, CA) and bathed in saline. The dorsal sides of the second through fifth abdominal ganglia (A2-A5) were desheathed to allow microelectrodes to access the lateral neuropil (LN) (Skinner, 1985).
Innervation of swimmerets. All the motor neurons that innervate a given swimmeret have cell bodies located in the same ganglion (Davis, 1971; Mulloney et al., 1990) (C. Sherff and B. Mulloney, unpublished data) and their axons exit the ganglion through the same N1 (Davis, 1971; Stein, 1971; McDonald, 1981; Sherff and Mulloney, unpublished data). In this species, PS and RS motor axons are segregated into two different branches of N1: PSE and PSI motor neurons send their axons out the posterior, PS branch, whereas RSE and RSI motor neurons send their axons out the anterior, RS branch (Davis, 1971; McDonald, 1981).

The swimmeret motor pattern produced in the third abdominal ganglion (A3) was monitored bilaterally with extracellular pin electrodes placed on the anterior and posterior branches of each N1. Sometimes, N1 activity in other ganglia was also recorded. The swimmeret motor pattern is characterized by alternating bursts of action potentials in PSE and RSE motor neurons (Fig. 1). Sometimes, as in the RS recording in Figure 1, 


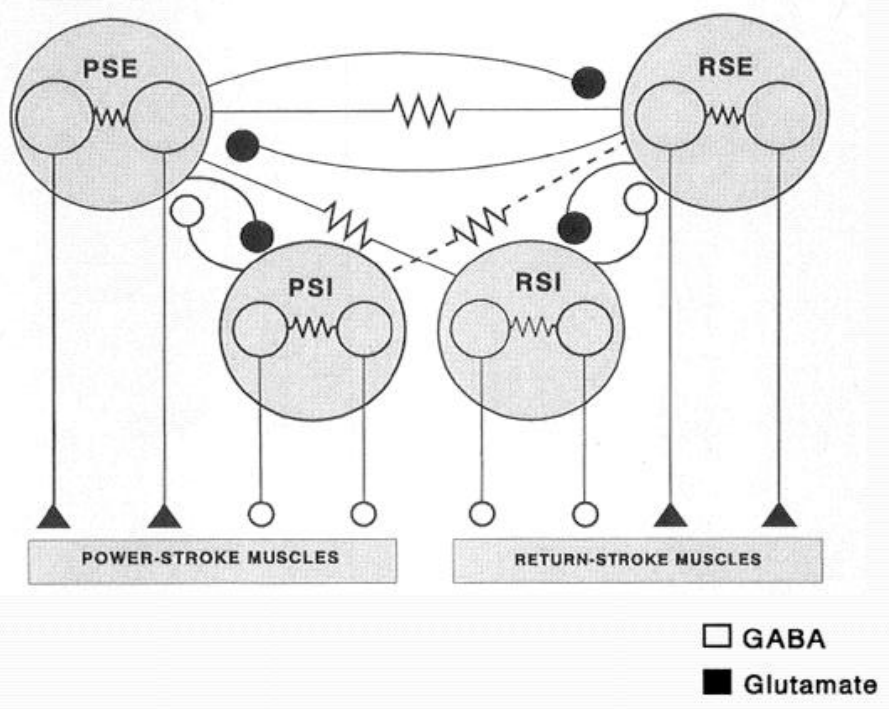

Figure 2. Summary diagram of the motor neuron model of the swimmeret pattern generator. The four groups of swimmeret motor neurons (PSE, RSE, PSI, and RSI) are represented by the large, shaded ellipses. Within each ellipse, two electrically coupled neurons in the group are shown as circles. Motor neurons synapse both peripherally onto muscles and centrally onto other swimmeret neurons. Electrical synapses are symbolized by resistor symbols, inhibitory chemical synapses by small circles, and excitatory chemical synapses by triangles.

bursts of impulses in inhibitory motor axons alternate with those of the excitors (Stein, 1971; Heitler, 1978).

Motor neurons could be distinguished by their electrical activity from the three other neurons that have central cell bodies and axons in N1: the segmental giant interneuron (Roberts et al., 1982; Heitler and Darrig, 1986) and the two nonspiking stretch receptors (Heitler, 1982).

Recordings from motor neurons. Intracellular recordings from swimmeret motor neurons were made with microelectrodes inserted into their processes in the LN. Microelectrodes were filled either with $2.5 \mathrm{M} \mathrm{KCl}$, or with $3 \mathrm{M} \mathrm{KAc}$ plus $1 \mathrm{mM} \mathrm{KCl}$, or with $5 \%$ Neurobiotin (Vector Laboratories, Burlingame, CA) in $0.2 \mathrm{M}$ Tris buffer plus $0.5 \mathrm{M} \mathrm{KCl}$. Tip resistances ranged from 20 to $30 \mathrm{M} \Omega$. Most microelectrode recordings were made in current-clamp mode. Input resistance $\left(R_{\text {in }}\right)$ was measured by injecting motor neurons with $1 \mathrm{nA}$ pulses at $0.5 \mathrm{~Hz}$. Reversal potentials $\left(E_{\mathrm{R}}\right)$ were measured by changing membrane potentials $\left(V_{\mathrm{m}}\right)$ in discontinuous current-clamp (DCC) mode and recording the voltage change imposed on the cell by application of GABA, L-glutamate, or their receptor agonists or antagonists. Recordings were amplified using an Axoclamp (Axon Instruments, Foster City, CA) and stored on VCR tape with a NeuroCorder (Neurodata Instruments, Delaware Water Gap, PA). Data were played back on an ES1000 electrostatic recorder (Gould, Cleveland, $\mathrm{OH}$ ) or a Gould 2400 pen recorder. They were digitized with the pClamp system (Axon Instruments) for further analysis.

Drug application. GABA, L-glutamate, and other drugs were applied locally in the LN (Fig. 1) by pressure ejection through a multibarreled micropipette (World Precision Instruments, New Haven, CT). The pressure ejection pipettes were pulled on a PE-2 vertical puller (Narashige, Greenvale, NY), and their tips were then broken manually under a dissecting microscope. The following solutions were made in regular crayfish saline for pressure ejection: $1 \mathrm{~mm}$ GABA (Research Biochemicals, Natick, MA), $1 \mathrm{~mm}$ L-glutamate (Research Biochemicals), $0.1 \mathrm{~mm}$ muscimol (Research Biochemicals), $0.1 \mathrm{~mm}$ ibotenic acid (Research Biochemicals), $0.1 \mathrm{~mm}$ baclofen (Sigma, St. Louis, MO), $0.1 \mathrm{~mm} \mathrm{GABA}_{\mathrm{C}}$ receptor agonist cis-4-aminocrotonic acid (CACA) (Tocris Neuramin, Bristol, UK). The GABA antagonists bicuculline methochloride $(0.1 \mathrm{~mm}$, Sigma), bicuculline methiodide $(0.1 \mathrm{~mm}$, Sigma $)$, and picrotoxin $(1 \mu \mathrm{M}$ to $100 \mu \mathrm{M}$, Research Biochemicals) were superfused into the bath via a gravity-driven perfusion system.

Block of synaptic transmission. Synaptic input to the motor neurons could be blocked by changing the external $\mathrm{Ca}^{2+}$ and $\mathrm{Mg}^{2+}$ concentrations. We perfused the bath with a modified saline that contained $20 \times$ normal $\left[\mathrm{Mg}^{2+}\right], 1 / 5$ normal $\left[\mathrm{Ca}^{2+}\right]$, and $3 / 5$ normal $\left[\mathrm{Na}^{+}\right]$to block synaptic transmission. This modified saline blocked spontaneous firing in
$\mathrm{N} 1$ and spontaneous PSPs in intracellular recordings of swimmeret motor neurons. To ensure that synaptic transmission was blocked, N1 nerves and the individual motor neurons were stimulated independently to produce action potentials. In high $\mathrm{Mg}^{2+}$ saline, stimulation of $\mathrm{N} 1$ produced an antidromic action potential in the motor neuron but not the PSPs normally seen in regular saline. When a motor neuron was stimulated with a pulse of current through the microelectrode, the action potential in its axon appeared in the recording from $\mathrm{N} 1$, but no other neurons responded to this stimulus.

Identification of synapses between pairs of motor neurons. Simultaneous intracellular recordings were made from pairs of swimmeret motor neurons. Depolarizing and hyperpolarizing currents were injected into each neuron to test for interactions between them. If depolarizing one neuron caused a hyperpolarization of the other, we suspected an inhibitory chemical connection. If depolarizing one neuron caused a depolarization of the other, but hyperpolarizing the first also hyperpolarized the second, we suspected a nonrectifying electrical connection or a graded excitatory chemical connection. When there was evidence of direct, electrical connections between neurons, the strengths of their synapses were calculated by measuring coupling coefficients (Bennett, 1977).

To determine whether two motor neurons were connected monosynaptically or by a polysynaptic pathway, we measured the delay between the onset of the voltage response to a large current pulse $(5-20 \mathrm{nA})$ injected into one cell and the onset of the voltage response in the postsynaptic cell. The averages of five to ten responses were reported. We were unable to test the ability of a connection to follow impulses in a putative presynaptic motor neuron 1:1 at high frequencies $(>100 \mathrm{~Hz})$ because the connections were too weak; we were also unable to test the effects of high $\mathrm{Ca}^{2+}$ saline because of the difficulty in holding two neuropil recordings long enough for a complete exchange of the bathing solution. Instead, we compared the latencies found in our experiments with synaptic latencies reported for other crayfish synapses, in which monosynapticity or polysynapticity has been confirmed by anatomical or the above-mentioned physiological criteria.

Dye coupling to individual motor neurons. Motor neurons were first identified physiologically. Neurobiotin was then ionophoresed into the cells with $+5 \mathrm{nA}$ current pulses, $250 \mathrm{msec}$ long at $2 \mathrm{~Hz}$, for at least $20 \mathrm{~min}$ and as long as $2.25 \mathrm{hr}$. After a cell was filled, the ganglion containing the filled cell was removed and immediately fixed in a solution of $4.0 \%$ paraformaldehyde and $0.2 \%$ picric acid. Neurobiotin diffused throughout the cell during the fill, labeling the fine neuropil branches even on the contralateral side of the ganglion. If the ganglion was not fixed soon after the fill, but instead after a period of 1 to $3 \mathrm{hr}$ to allow for further diffusion of Neurobiotin, then labeling was weak.

Ganglia were fixed overnight and then processed for Cy3-Streptavidin (Jackson Immunoresearch, West Grove, PA) secondary labeling. Ganglia were washed in Dulbecco's PBS (Sigma) and dehydrated to $70 \%$ ethanol to increase permeability. They were then rehydrated to PBS and preincubated with $0.3 \%$ reduced Triton X-100 (Sigma) in PBS. The ganglia were incubated for 14-18 hr with Cy3-Streptavidin, diluted 1:200 in 0.3\% Triton X-100 in PBS. The tissue was then rinsed in PBS, dehydrated in ethanol, and cleared in methyl salicylate. The labeled cells were studied and photographed using a fluorescence microscope equipped with high numerical aperture planapochromatic optics (Nikon, Garden City, NY).

\section{RESULTS}

\section{Identification of swimmeret motor neurons}

Neurons could be identified as RS or PS motor neurons by the presence of an axon in either the anterior (RS) or posterior (PS) branch of N1 (Fig. 3). In Figure 3, action potentials elicited by depolarizing each motor neuron were followed 1:1 by action potentials in the nerve recordings. Antidromic stimulation of each branch confirmed the presence of the axon in one of them (not shown). RS and PS motor neurons could then be assigned to the appropriate excitor or inhibitor group by the timing of their oscillations with respect to the motor pattern (Davis, 1969; Heitler, 1978). Currents injected into motor neurons often excited synergist motor neurons (Fig. 3A, asterisks) and inhibited antagonist motor neurons (Fig. $3 B$, arrows). The RSE motor neuron in Figure $3 A$ was classified as an excitor because it oscillated in phase with bursts of RS units and because depolarizing it excited other 
A

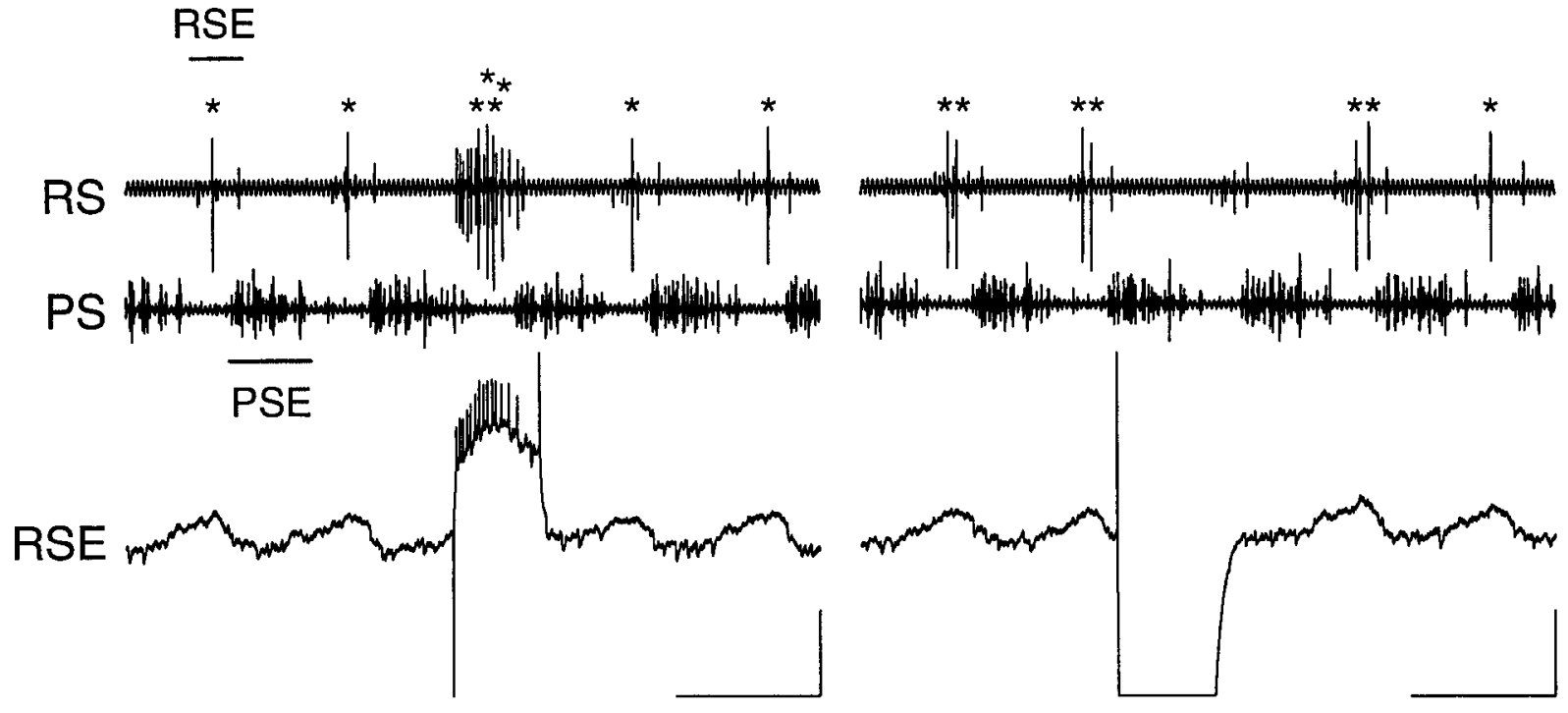

B
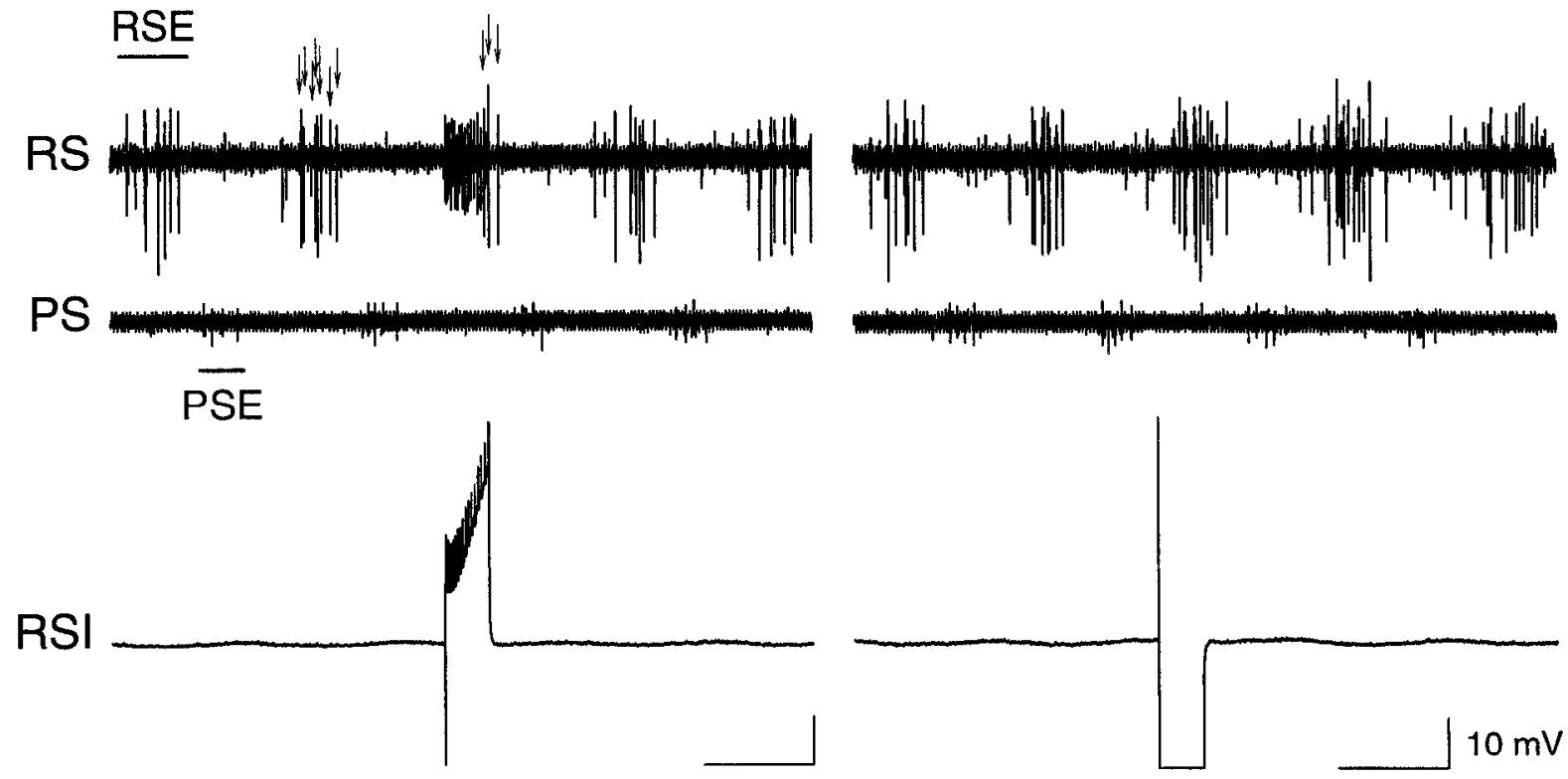

$0.5 \mathrm{~s}$.

Figure 3. Swimmeret motor neurons could be identified by the location of their axons in branches of N1, the phase of their oscillations relative to bursts of action potentials in N1, and by their effects on other motor neurnns. $A$, This RSE motor neuron had an axon in the RS branch of N1 and oscillated in phase with bursts of impulses in RS motor neurons. Depolarizing this neuron caused it to fire action potentials and also increased the firing frequency of another, larger RS unit (asterisks). Hyperpolarizing this cell inhibited that same larger unit. $B$, This RSI had an axon in the RS branch, but oscillated in phase with bursts of impulses in PS motor neurons. Depolarizing this neuron inhibited most of the units that usually fircd during RS bursts (anows). The motor pattern was unaffected by hyperpolarizing this RSI. Current injection: $A, \pm 3 n \mathrm{~A} ; B,+12,-10 \mathrm{nA}$. The hyperpolarizing current pulses have been truncated because the bridge could not be balanced. 
Table 1. Changes in the swimmeret motor pattern in response to GABA and glutamate

\begin{tabular}{llcc} 
& & GABA & Glutamate \\
\hline PS Activity & Increased & 1 & $6^{a}$ \\
& Decreased & 80 & 20 \\
& No change & 19 & 21 \\
\multirow{5}{*}{ RS Activity } & Increased & $14^{a}$ & $6^{a}$ \\
& Decreased & 62 & 19 \\
& No change & 24 & 22 \\
$n$ trials & & 100 & 47
\end{tabular}

in 53 nerve cords in 23 nerve cords

Responses reported here were measured from $\mathrm{N} 1$ recordings in the same hemiganglion to which the transmitter was applied.

${ }^{a}$ In these trials, most $\mathrm{N} 1$ units were inhibited, but firing frequency increased for one or two units.

RS motor neurons; the most obvious of these was the large unit that normally fired once in each cycle but fired 4 times when the RSE motor neuron was depolarized (asterisks). Hyperpolarizing current injected into this neuron inhibited synergist RS units.

The RSI motor neuron in Figure $3 B$ was classified as an inhibitor because its axon was in the RS branch, but it oscillated in phase with bursts of PS units. The amplitude of its oscillation was small $(\sim 1 \mathrm{mV})$. Depolarizing this cell inhibited other RS units (arrows); only three action potentials occurred during the burst when the RSI was depolarized, compared with seven or eight units in the other bursts. Hyperpolarizing this cell did not affect the firing pattern of any other N1 units.

\section{Inhibition of the motor pattern and motor neurons by GABA and glutamate}

We tested the effects of GABA and glutamate on the swimmeret motor pattern and on individual swimmeret motor neurons by pressure ejecting the transmitters directly into the LN, where swimmeret motor neurons have their central synapses. In our experiments, both glutamate and GABA inhibited expression of the swimmeret motor pattern by the crayfish CNS and inhibited activity of individual swimmeret motor neurons. These results were important because, in a previous study (Mulloney et al., 1987), bath application of GABA and glutamate did not affect the swimmeret system. Bath perfusion of neurotransmitters could have been ineffective if uptake mechanisms (Kaila et al., 1992; Kerrison and Freschi, 1992) or degradative enzymes (Braun and Mulloney, 1995) prevented access to synapses, or if receptors became desensitized (Dudel et al., 1990; El Manira and Clarac, 1994).

\section{Disruption of the motor pattern}

When GABA or glutamate was pressure-ejected into one $\mathrm{LN}$, it disrupted the normal swimmeret activity in that hemiganglion but not in other ganglia. The responses to GABA and glutamate in all experiments are summarized in Table 1. In most trials when GABA was pressure-ejected, the number of action potentials occurring in the PS recordings decreased, or firing was abolished completely. There was no response to GABA in almost $20 \%$ of the trials, and in one case a single PS unit was excited. RS responses to GABA were more variable. Either firing stopped or the frequency of impulses was reduced in more than half of the trials. In a few cases, most RS units ceased firing or decreased firing frequency, but one or two RS units actually increased their firing frequency. There was no RS response to GABA in $24 \%$ of the trials. Pressure ejection of GABA into the left $\mathrm{LN}$ of $\mathrm{A} 3$ in the preparation shown (Fig. 4, left) disrupted the motor pattern in both RS and PS branches of N1 on the same side of the ganglion. Firing in the PS branch was inhibited, whereas a few RS units began to fire tonically. With careful placement of the pressureejection pipette above the LN, close to the surface of the ganglion, GABA responses were often limited to one hemisegment of $\Lambda 3$. The smaller contralateral responses that were sometimes seen (Fig. 4, left) were likely attributable to diffusion of transmitter from the pipette to the contralateral hemiganglion.

Glutamate also disrupted the motor pattern, although its effects were often smaller than those seen with GABA. Glutamate inhibited firing of PS units in almost half of the trials and had no effect on PS firing in a similar number of trials. In six cases, most PS units were inhibited, but one or two units increased their firing frequency. RS units responded similarly to glutamate; firing frequency of all units decreased in fewer than half of the trials. In approximately half, firing frequency was unchanged, and in a few cases the firing frequency of one or two units increased. An example of the effect of glutamate on the motor pattern is shown in Figure 4 (right panel). When glutamate was pressure-ejected into the left LN, firing in the PS recording increased and one small unit began firing tonically, whereas the firing frequency decreased in the RS record.

Application of GABA and glutamate to one hemiganglion did not affect the ongoing motor pattern in more anterior or more posterior ganglia (data not shown). Thus, the sites of action of both GABA and glutamate appeared to be within the hemisegmental swimmeret network. When neurotransmitter was applied to other ganglia (A2, A4, or A5), the results were similar; GABA and glutamate disrupted the motor pattern in the hemiganglion in which it was applied, with little effect on the contralateral hemiganglion and no effect on more anterior or posterior ganglia.

Variations in the responses of the motor pattern to GABA and glutamate were probably attributable to a combination of physiological differences between preparations and differences in the exact location of the pipette tip within the LN. Differences in the physiological state of the animal before dissection might cause differences in the responses of the nervous system to applied neurotransmitters.

\section{GABA and glutamate acted directly on swimmeret motor neurons}

Both GABA and glutamate usually hyperpolarized $V_{\mathrm{m}}$ and decreased $R_{\text {in }}$ of swimmeret motor neurons (Table 2). The GABA responses of 87 motor neurons were recorded. $R_{\text {in }}$ decreased by at least $0.5 \mathrm{M} \Omega$ in 64 of these when $1 \mathrm{~mm}$ GABA was pressureejected. The other 23 motor neurons showed either no response

\begin{tabular}{lrc}
\hline $\begin{array}{l}\text { Table 2. Changes in motor neuron properties caused by GABA and } \\
\text { glutamate (mean } \pm \text { SD) }\end{array}$ & \\
& $1 \mathrm{mM}$ GABA & $1 \mathrm{mM}$ Glutamate \\
\hline$\Delta V_{m}(\mathrm{mV})$ & $-2.7 \pm 4.1$ & $-0.9 \pm 2.4$ \\
& $(n-64)$ & $(n=26)$ \\
$\Delta R_{\text {in }}(\mathrm{M} \Omega)$ & $-3.8 \pm 6.3$ & $-2.5 \pm 3.3$ \\
$\%$ change & $-31 \%$ & $-24 \%$ \\
& $(n=64)$ & $(n=26)$ \\
$E_{R}(\mathrm{mV})$ & $-66.3 \pm 9.2$ & $-64.0 \pm 11.1$ \\
& $(n=36)$ & $(n=4)$ \\
\hline
\end{tabular}




\section{.............

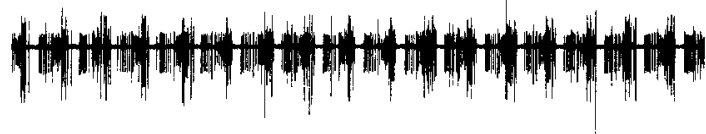

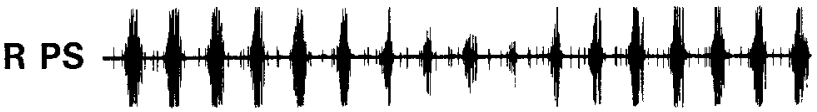

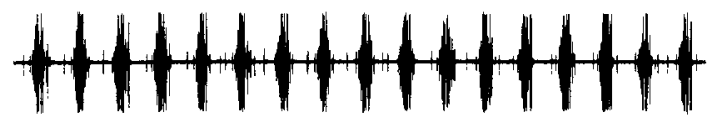

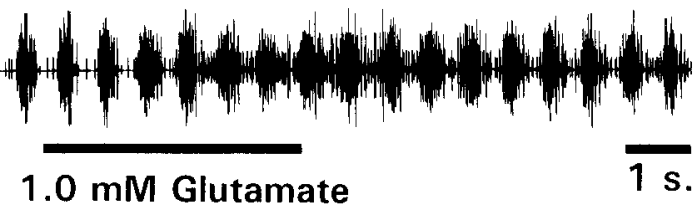

$1.0 \mathrm{mM}$ GABA

$1 \mathrm{~s}$.

Figure 4. GABA and glutamate disrupted the swimmeret motor pattern. Simultaneous recordings from the RS and PS branches of N1 from right and left sides of an A3. Horizontal bars show the interval when GABA or Glutarrate was injected into the left LN.

to GABA or a change of $<0.5 \mathrm{M} \Omega$; these latter were not included in the tally because changes so small might have been caused by background fluctuations in $R_{\text {in }}$ rather than by applied GABA. The large standard deviations were the result of a non-normal distribution of $V_{\mathrm{m}}$ and $R_{\text {in }}$ changes that were skewed toward smaller values. In the example shown in Figure 5 (top left), the PS motor neuron hyperpolarized from -57 to $-60 \mathrm{mV}$, and its $R_{\text {in }}$ decreased from 7.7 to $6.0 \mathrm{M} \Omega(22 \%)$ when $1 \mathrm{~mm}$ GABA was pressure-ejected into the $\mathrm{LN}$.

Motor neuron responses to glutamate were similar to their responses to GABA (Table 2). The glulanale responses of 40 motor neurons were recorded. Twenty-six of them displayed measurable responses ( $>0.5 \mathrm{M} \Omega$ change in $R_{\text {in }}$ ). The cell in Figure 5 (top right panel) hyperpolarized from -53 to $-56 \mathrm{mV}$, and its $R_{\mathrm{in}}$ decreased from 8.3 to $3.1 \mathrm{M} \Omega(63 \%)$ when $1 \mathrm{~mm}$ glutamate was pressure-ejected.

GABA and glutamate might have acted directly on the motor neurons, or they might have acted on interneurons of the swimmeret network, affecting the motor neurons only indirectly. To discover whether these inhibitory actions were direct, synaptic input to the motor neurons was blocked by perfusing the bath with a high $\mathrm{Mg}^{2+}$-low $\mathrm{Ca}^{2+}$ saline. In the altered saline, all spontaneous firing in the N1 branches ceased, and spontaneous PSPs disappeared from intracellular records, indicating that synaptic transmission had ceased (Fig. 5, bottom panels). Under these conditions, depolarization of the motor neuron caused only one N1 unit to fire, and stimulating N1 elicited an antidromic spike in the motor neuron but not the PSPs that normally would appear in response to such stimulation. Nonetheless, the responses of motor neurons to both GABA (25/26) and glutamate (13/14) persisted in high $\mathrm{Mg}^{2+}$ (Fig. 5), indicating that the motor neurons themselves responded to the applied neurotransmitters.

Motor neurons in each functional category (PSE, RSE, PSI, and RSI) were similarly inhibited by GABA and glutamate (Table $3)$. $R_{\text {in }}$ decreased and $V_{\mathrm{m}}$ usually hyperpolarized. Glutamate re- sponses were measured in three of the four groups: PSE, RSE, and RSI. We did not record from any PSIs when testing glutamate. Small changes in $V_{\mathrm{m}}$, e.g., $-0.5 \mathrm{mV}$ for RSI, occurred because the $E_{\mathrm{R}}$ for both GABA and glutamate responses were near resting potential, so responses were sometimes depolarizing, and occasionally $V_{\mathrm{m}}$ did not change. In Table 3 , the sum of the numbers $(n)$ of neurons tested in each group is less than the total number of motor neurons tested (Table 2), because it includes data only from cells that could be classified with certainty (see Materials and Methods).

\section{$E_{\mathrm{R}}$ suggest that both GABA and glutamate gate $\mathrm{Cl}^{-}$currents}

Although $R_{\text {in }}$ usually decreased when GABA or glutamate was applied, changes of $V_{\mathrm{m}}$ in motor neurons were not always hyperpolarizing; 14 of 64 GABA responses and 9 of 26 glutamate responses were depolarizing. To begin to describe these

\footnotetext{
Table 3. Changes in membrane properties of different types of swimmeret motor neurons in response to GABA and glutamate (mean \pm SD)
}

1. $\mathrm{mM} \mathrm{GABA}$

\begin{tabular}{lllll}
\hline $\begin{array}{l}\text { Neuron } \\
(n)\end{array}$ & $\begin{array}{l}\text { PSE } \\
(20)\end{array}$ & $\begin{array}{l}\text { PSI } \\
(1)\end{array}$ & $\begin{array}{l}\text { RSE } \\
(3)\end{array}$ & $\begin{array}{l}\text { RSI } \\
(3)\end{array}$ \\
\hline$\Delta V_{m}(\mathrm{mV})$ & $-4.4 \pm 4.0$ & -6.8 & $-4.2 \pm 6.8$ & $-0.5 \pm 1.1$ \\
$\Delta R_{\text {in }}(\mathrm{M} \Omega)$ & $-2.3 \pm 1.9$ & -7.0 & $-5.8 \pm 9.0$ & $-0.9 \pm 1.7$ \\
\hline
\end{tabular}

1 mM Glutamate

\begin{tabular}{lllll}
\hline $\begin{array}{l}\text { Neuron } \\
(n)\end{array}$ & PSE & $\begin{array}{l}\text { PSI } \\
(0)\end{array}$ & $\begin{array}{l}\text { RSE } \\
(1)\end{array}$ & $\begin{array}{l}\text { RSI } \\
(3)\end{array}$ \\
\hline$\Delta V_{m}(\mathrm{mV})$ & $-1.2 \pm 2.7$ & - & 0.7 & $-0.3 \pm 3.1$ \\
$\Delta R_{\mathrm{ln}}(\mathrm{M} \Omega)$ & $-3.0 \pm 3.4$ & - & -2.4 & $-4.1 \pm 5.6$ \\
\hline
\end{tabular}




\section{Saline}
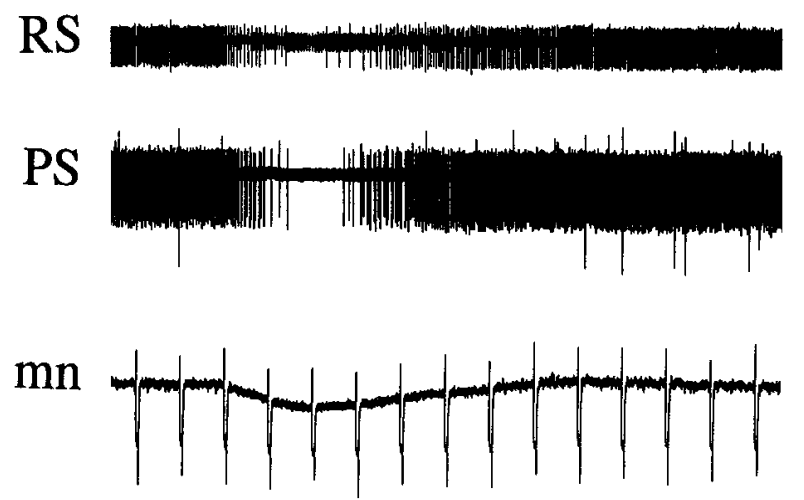
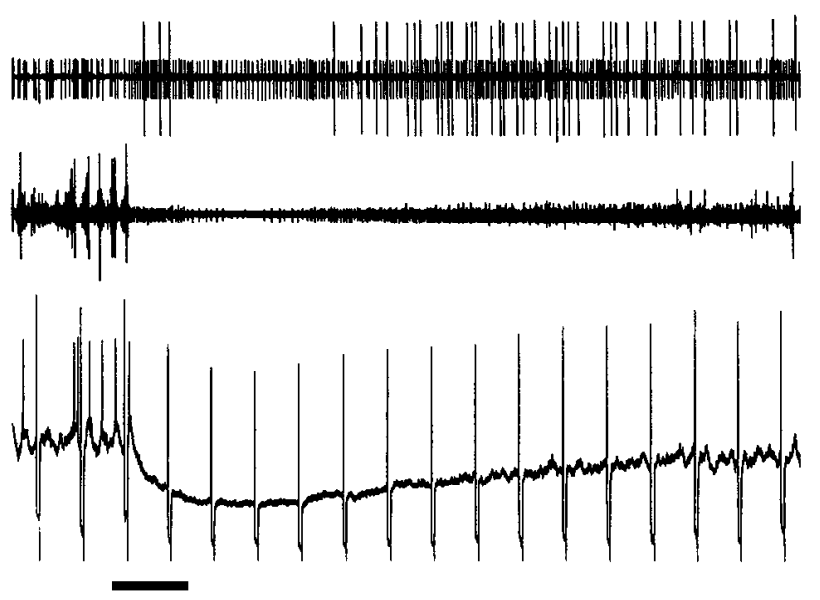

\section{High $\mathrm{Mg}^{2+}-$ Low $\mathrm{Ca}^{2+}$ Saline}
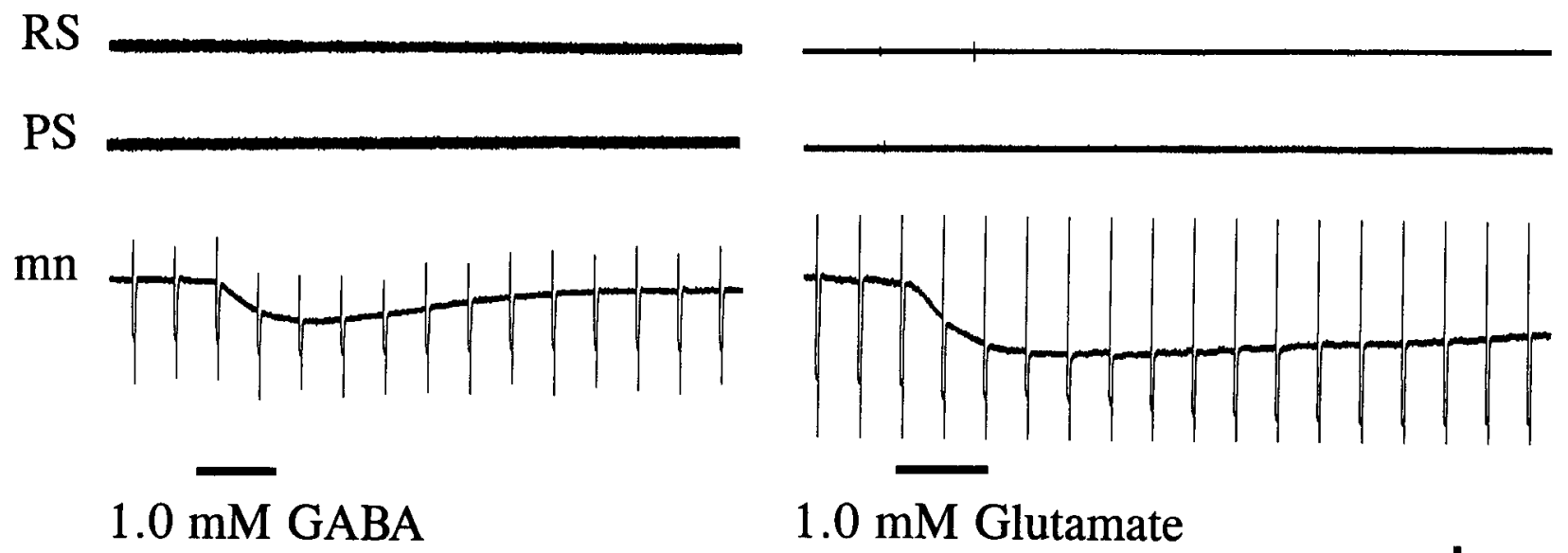

$1.0 \mathrm{mM}$ Glutamate

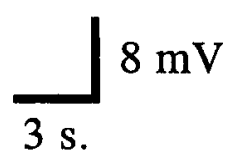

Figure 5. GABA and glutamate directly inhibited swimmeret motor neurons. Pressure ejection of GABA (interval marked by horizontal bar) led to a hyperpolarization of the resting potential of the motor neuron and a decrease in its $R_{\text {in }}$ (top left). $R_{\text {in }}$ was monitored by injecting the motor neuron with $-1 \mathrm{nA}$ pulses at $0.5 \mathrm{~Hz}$. In a different motor neuron, pressure ejection of glutamate caused a similar hyperpolarization and $R_{\text {in }}$ decrease $(t o p$ right). These responses to GABA and glutamate persisted when synaptic transmission was blocked by superfusing the bath with high $\mathrm{Mg}^{2+}-$ low $\mathrm{Ca}^{2+}$ saline (lower left and right).

inhibitory currents, we measured the $E_{\mathrm{R}}$ of GABA and glutamate responses in DCC mode by injecting long-duration current pulses to change $V_{\mathrm{m}}$ and observing the additional voltage changes that occurred when transmitter was applied through the pressure pipette. The $E_{\mathrm{R}}$ of responses to both transmitters were near the resting membrane potential, so small changes in $V_{\mathrm{m}}$ would change the polarity of the response. For both GABA and glutamate, $E_{\mathrm{R}}$ averaged approximately $-65 \mathrm{mV}$ (Table 2). When we could measure $E_{\mathrm{R}}$ of both GABA and glutamate responses in the same motor neuron, they were the same (Fig.
6). In this cell, $V_{\mathrm{m}}$ was $-52 \mathrm{mV}$, and the $E_{\mathrm{R}}$ for GABA and glutamate were the same, approximately $-60 \mathrm{mV}$. In the entire set of measurements, $E_{\mathrm{R}}$ ranged between -88 and $-50 \mathrm{mV}$ for GABA and between -92 and $-44 \mathrm{mV}$ for glutamate. These ranges probably result from our inability to clamp the entire neuron to the same potential.

The similar $E_{\mathrm{R}}$ of the GABA and glutamate responses, along with the accompanying decrease in $R_{\text {in }}$, suggest that both GABA and glutamate gate an inhibitory current that is predominantly carried by $\mathrm{Cl}^{-}$. We were unable to test this idea directly because 
1.0 mM GABA

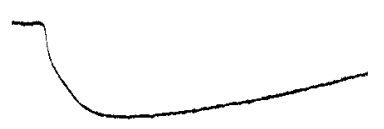

$-51$

$1.0 \mathrm{mM}$ Giutamate
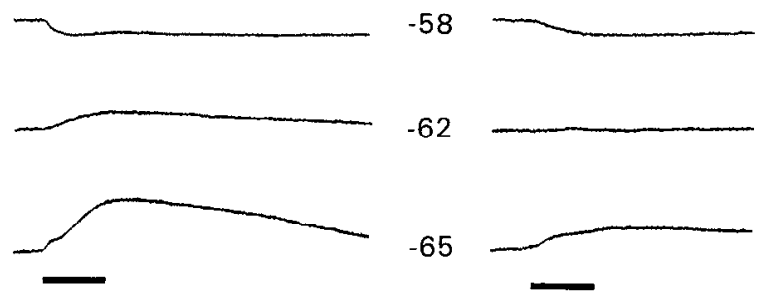

$-65$

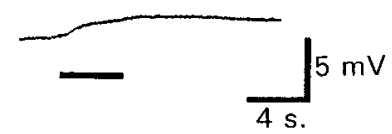

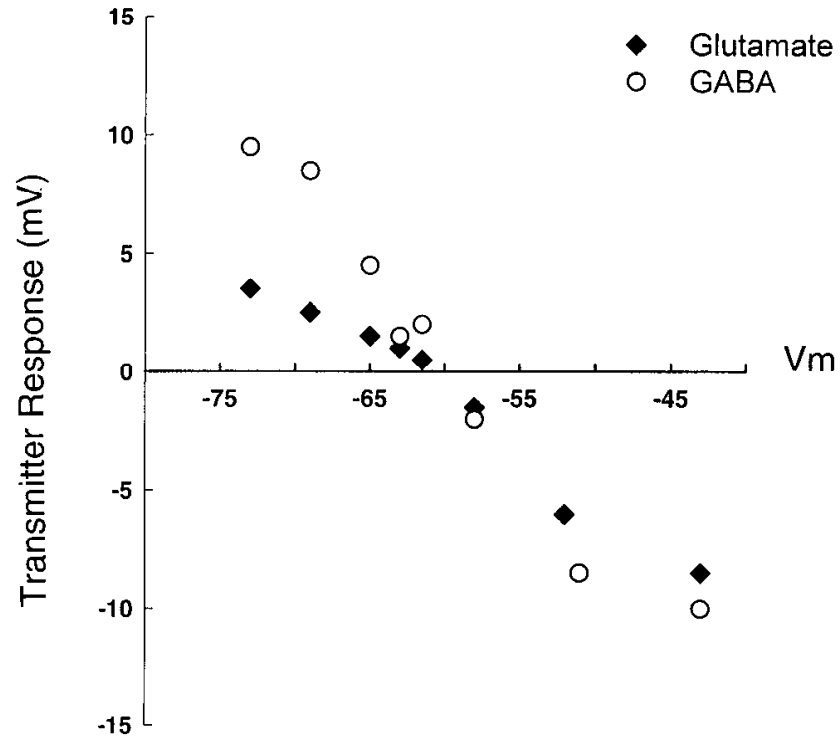

Figure 6. $E_{\mathrm{GABA}}$ and $E_{\text {glutamate }}$ were measured in DCC mode. The $V_{\mathrm{m}}$ of the cell shown in the top was shifted to the potentials indicated. GABA (left) or glutamate (right) was then pressure-ejected during the interval marked by the bars. The change in $V_{m}$ that followed transmitter application was measured and plotted as a function of the steady-state $V_{\mathrm{m}}$ (bottom). Both responses reversed near $-60 \mathrm{mV}$. The preparation was bathed in high $\mathrm{Mg}^{21}$-low $\mathrm{Ca}^{21}$ saline to block synaptic activity.

we could not consistently shift the $E_{\mathrm{R}}$ of either the GABA or the glutamate response by changing external concentrations of $\mathrm{Cl}^{-}$or $\mathrm{K}^{+}$. Resting $\mathrm{K}^{+}$and $\mathrm{Cl}^{-}$currents could account for this difficulty (Fuchs and Getting, 1980).

\section{Muscimol and ibotenic acid also inhibited swimmeret motor neurons}

To see whether the central receptors for GABA and glutamate on these motor neurons were like other crustacean receptors, we observed the responses of swimmeret motor neurons to different GABA and glutamate agonists and antagonists. In five preparations tested, the $\mathrm{GABA}_{\mathrm{A}}$ agonist muscimol disrupted the swimmeret motor pattern by inhibiting firing or decreasing firing frequency in both the RS and PS nerve branches (Fig. 7A). In these preparations, the seven motor neurons tested were inhibited by 1 mM GABA. These included two RS motor neurons and five PS motor neurons, one of which could be identified as a PSE. They all displayed similar responses to $0.1 \mathrm{mM}$ muscimol. The $R_{\text {in }}$ of the motor neuron in Figure $7 A$ decreased $4.5 \mathrm{M} \Omega$, from 15.3 to 10.8 $\mathrm{M} \Omega$, and the $V_{\mathrm{m}}$ hyperpolarized by $7 \mathrm{mV}$, from -45 to $-52 \mathrm{mV}$ with pressure ejection of GABA. Muscimol ( $0.1 \mathrm{~mm})$ caused a similar response, decreasing $R_{\text {in }}$ by $4.5 \mathrm{M} \Omega$ and hyperpolarizing the cell by $12 \mathrm{mV}$.

Both GABA responses and muscimol responses persisted when synaptic transmission was blocked by high $\mathrm{Mg}^{2+}-$ low $\mathrm{Ca}^{2+}$ saline. The responses to muscimol of four of these seven motor neurons (3 PS and $1 \mathrm{RS}$, in 3 preparations) were tested both in normal saline and in high $\mathrm{Mg}^{2+}$-low $\mathrm{Ca}^{2+}$ saline (data not shown).

Ibotenic acid, an agonist of the glutamate-gated $\mathrm{Cl}^{-}$channel receptor in arthropods (Lea and Usherwood, 1973; Cull-Candy, 1976; Lingle and Marder, 1981), inhibited swimmeret motor neurons. In two preparations, ibotenic acid inhibited firing of both RS and PS motor axons (Fig. $7 B$ ). In this example, $0.1 \mathrm{~mm}$ ibotenic acid inhibited more N1 units than did $1.0 \mathrm{~mm}$ glutamate. All three motor neurons tested were inhibited both by glutamate and by ibotenic acid. These three included one RSE, one PSE, and a second PS motor neuron. In response to glutamate, $R_{\text {in }}$ of the motor neuron in Figure $7 B$ decreased 5.2 $\mathrm{M} \Omega$, from 8.3 to $3.1 \mathrm{M} \Omega$, and $V_{\mathrm{m}}$ hyperpolarized by $8 \mathrm{mV}$, from -53 to $-61 \mathrm{mV}$. Ibotenic acid caused a decrease in $R_{\text {in }}$ of 3.4 $\mathrm{M} \Omega$ and a hyperpolarization of $10 \mathrm{mV}$ in the same neuron. Two of these motor neurons, including the one in Figure $7 B$, were also tested during superfusion of the bath with high $\mathrm{Mg}^{2+}$-low $\mathrm{Ca}^{2+}$ saline. Both the glutamate and the ibotenic acid responses persisted when synaptic transmission was blocked (data not shown).

Table 4. Responses of swimmeret motor neurons to agonists and antagonists of GABA or glutamate

\section{GABA}

GABA Muscimol Bicuculline ${ }^{a}$ Baclofen CACA Picrotoxin ${ }^{a}$

\begin{tabular}{lllllll}
\hline All PS & $+(55)$ & $+(5)$ & $-(3)$ & $-(4)$ & $-(2)$ & $-(5)$ \\
PSE & $+(19)$ & $+(1)$ & $-(2)$ & 0 & $-(1)$ & 0 \\
PSI & $+(1)$ & 0 & 0 & 0 & 0 & 0 \\
All RS & $+(14)$ & $+(2)$ & $-(1)$ & $-(1)$ & $-(2)$ & 0 \\
RSE & $+(3)$ & 0 & $-(1)$ & 0 & $-(1)$ & 0 \\
RSI & $+(3)$ & 0 & 0 & 0 & 0 & 0
\end{tabular}

\begin{tabular}{llll} 
& \multicolumn{3}{c}{ Glutamate } \\
\cline { 2 - 4 } & Glutamate & Ibotenic acid & Picrotoxin $^{a}$ \\
\hline All PS & $+(18)$ & $+(2)$ & $+(1$ of 5$)$ \\
PSE & $+(6)$ & $+(1)$ & $+(1$ of 2$)$ \\
PSI & 0 & 0 & 0 \\
All RS & $+(8)$ & $+(1)$ & \\
RSE & $+(1)$ & $+(1)$ & 0 \\
RSI & $+(3)$ & 0 & 0 \\
\hline
\end{tabular}

+ , Responses were observed.

( ), Number of molor neurons tested.

- , No responses were observed.

0 , No data.

${ }^{a}$ Effect measured as a difference in response to neurotransmitter when agonist/ antagonist was present in or absent from the bath. 
A

RS

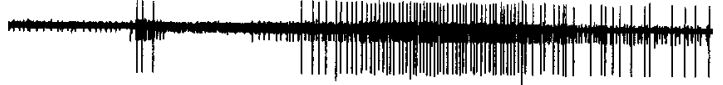

PS
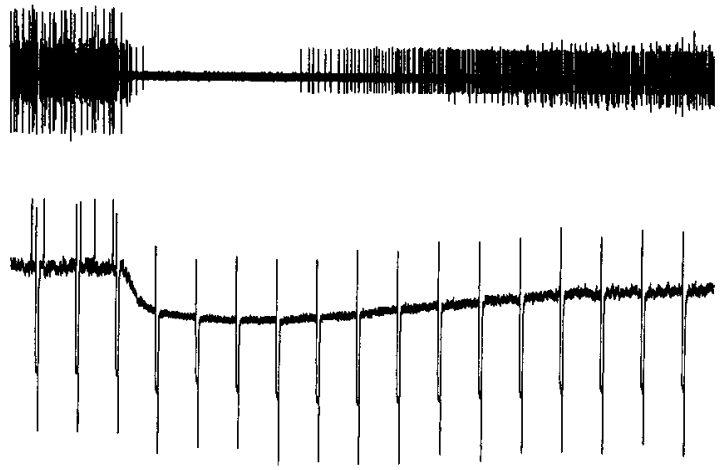

$1.0 \mathrm{mM} \mathrm{GABA}$
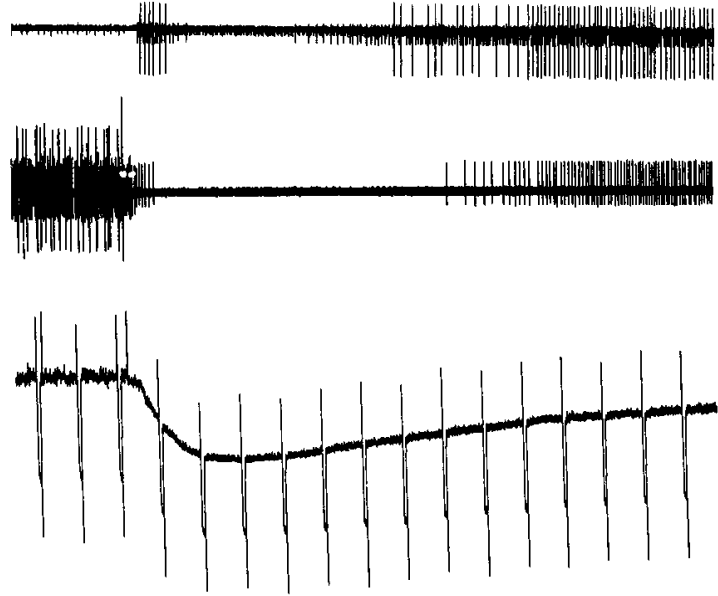

$0.1 \mathrm{mM}$ Muscimol

B

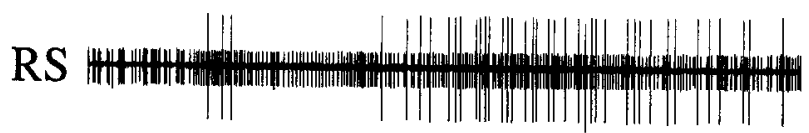

PS
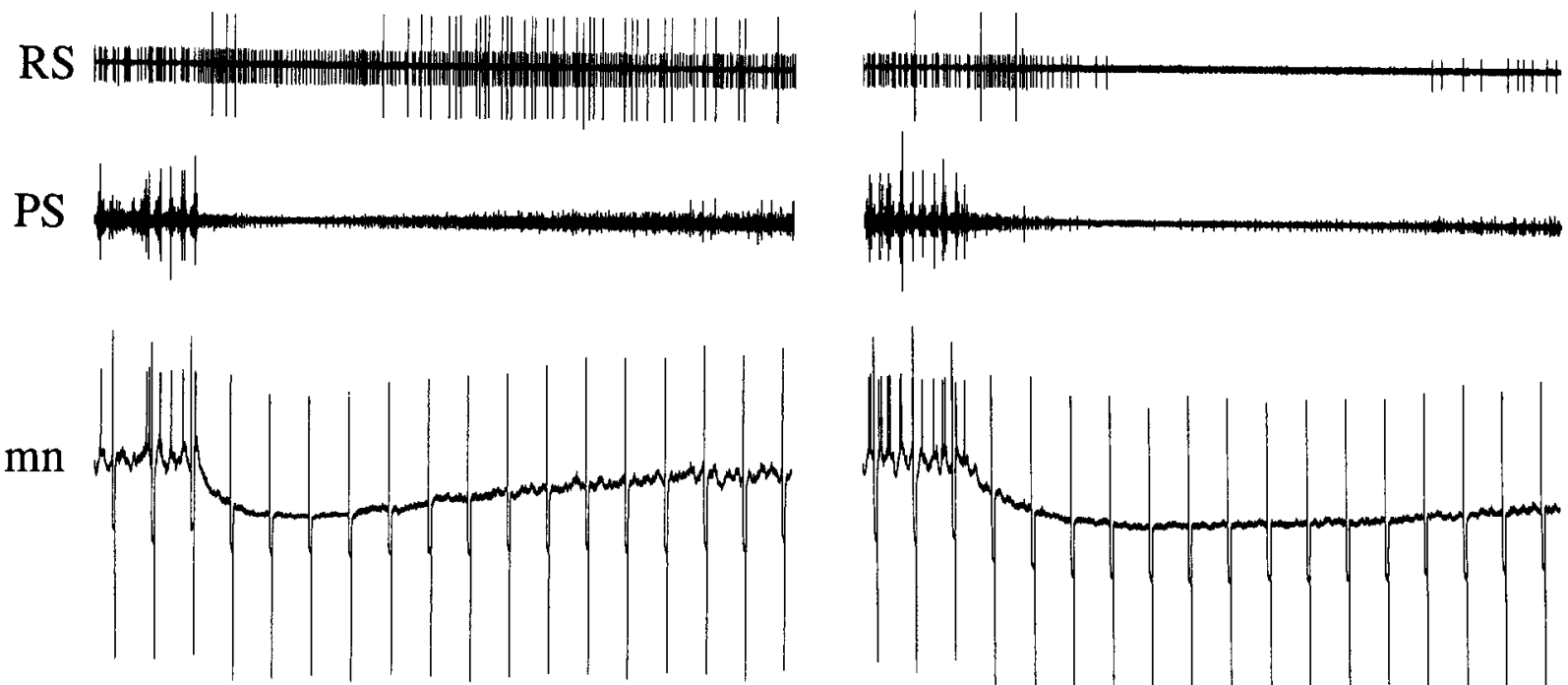

$1.0 \mathrm{mM}$ Glutamate

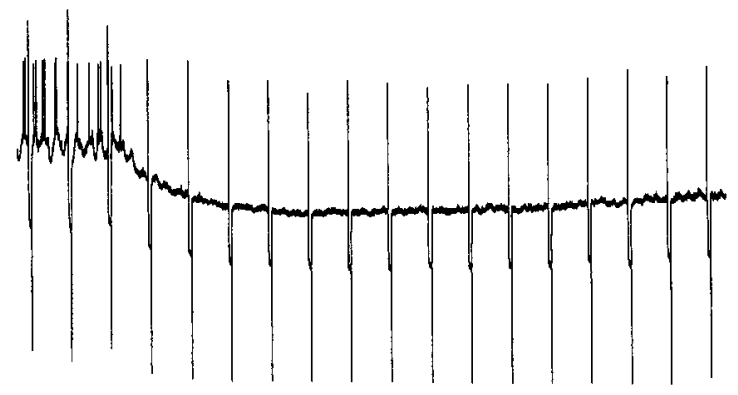

$0.1 \mathrm{mM}$ Ibotenic Acid

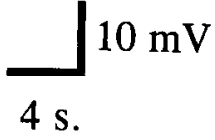

Figure 7. The actions of GABA and glutamate were mimicked by muscimol and ibotenic acid. $A$, The responses of the motor pattern and a motor neuron to GABA (left) and to muscimol (right) were similar. Both compounds inhibited firing in the RS and PS recordings, hyperpolarized the motor neuron, and decreased its $R_{\mathrm{in}} . B$, The motor pattern was disrupted by both glutamate and ibotenic acid. The motor neuron hyperpolarized and its $R_{\mathrm{in}}$ decreased after pressure ejection of either Glutamate or Ibotenic Acid.

\section{Pharmacological profile of the GABA responses}

To compare the swimmeret GABA receptors with other crustacean receptors, we tested the responses of swimmeret motor neurons to bicuculline, baclofen, CACA, and picrotoxin. Neither the $\mathrm{GABA}_{\mathrm{A}}$ antagonist bicuculline nor the $\mathrm{GABA}_{\mathrm{B}}$ agonist baclofen had any effect on swimmeret motor neurons (Table 4). 


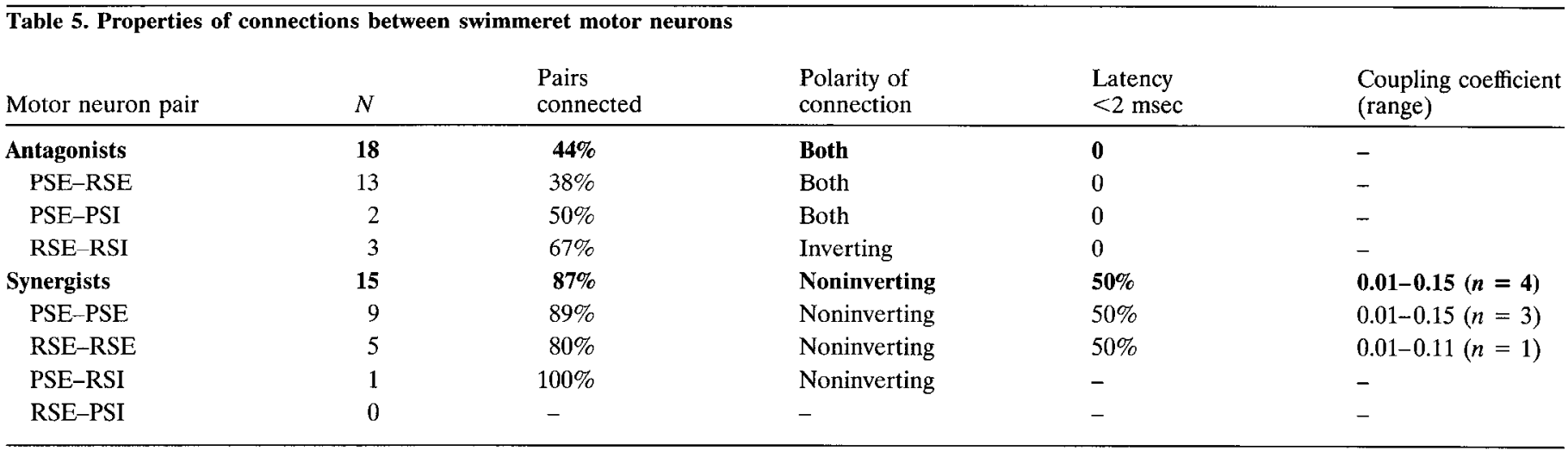

Superfusion of the bath with up to $0.1 \mathrm{~mm}$ bicuculline had no effect on the responses of four motor neurons to GABA. These four included two PSEs and one RSE in four preparations. Pressure ejection of $0.1 \mathrm{~mm}$ baclofen had no effect on $V_{\mathrm{m}}$ or $R_{\mathrm{in}}$ of four PS motor neurons and one RS motor neuron in five preparations.

In addition to the $\mathrm{GABA}_{\mathrm{A}}$ and $\mathrm{GABA}_{\mathrm{B}}$ agonists and antagonists, we also tested the effects of the $\mathrm{GABA}_{\mathrm{C}}$ receptor agonist CACA (Feigenspan et al., 1993; Qian and Dowling, 1993). $\mathrm{GABA}_{C}$ receptors gate $\mathrm{Cl}^{-}$channels but are insensitive to bicuculline, a profile similar to the GABA responses seen in this study. Howcver, $0.1 \mathrm{~mm}$ CACA had no effect on four motor neurons: 1 PS, 1 PSE, 1 RS, 1 RSE in three preparations. These results suggest that the GABA receptors in the crayfish CNS are different from the usual $\mathrm{GABA}_{\mathrm{A}}, \mathrm{GABA}_{\mathrm{B}}$, and $\mathrm{GABA}_{\mathrm{C}}$ subtypes.

\section{Picrotoxin blocked the responses of swimmeret motor neurons to glutamate}

Picrotoxin is a blocker of $\mathrm{Cl}^{-}$channels that are usually associated with the $\mathrm{GABA}_{\mathrm{A}}$ and $\mathrm{GABA}_{\mathrm{C}}$ receptors. Superfusion of the bath with 1-100 $\mu \mathrm{M}$ picrotoxin caused marked changes in the swimmeret motor pattern in six preparations. In four of these, picrotoxin was associated with increases in the number of $\mathrm{N} 1$ units firing and in the cycle frequency of the motor pattern. In the preparation shown in Figure 8, the firing frequency of individual units increased in $1 \mu \mathrm{M}$ picrotoxin (e.g., the small units that fired between bursts in both the PS and RS), and the number of different motor units that fired increased (Fig. 8A). The cycle frequency of the motor pattern increased 5\%, from 1.76 to 1.84 Hz. In $100 \mu \mathrm{M}$ picrotoxin, the motor pattern broke down; periods of intense, tonic firing of several units would be interrupted by periods of the usual motor pattern or periods of silence. In the other two preparations, concentrations as low as $1 \mu \mathrm{M}$ resulted in dissolution of the motor pattern. These data indicate that $\mathrm{Cl}^{-}$ channels are important for the operation of the swimmeret network.

Picrotoxin $(1 \mu \mathrm{M})$ decreased or eliminated the effects of glutamate on the motor pattern $(n=2)$, but it did not block the effects of GABA $(n=3)$. The GABA responses in control saline (Fig. $8 B$ ) and in the presence of $1 \mu \mathrm{M}$ picrotoxin (Fig. $8 C$ ) were similar. The small differences in the latency and strength of the inhibition might result from these GABA-gated channels being slightly picrotoxin-sensitive, or from a mix of picrotoxin-sensitive and picrotoxin-insensitive channels.

The responses of individual PS motor neurons to GABA $(n=5)$ and glutamate $(n=5)$ were measured in the presence and absence of picrotoxin. None of the GABA responses was reduced by picrotoxin (Table 4). Only one motor neuron showed any change in its response to glutamate, and this change was small: glutamate decreased its $R_{\text {in }}$ by $2.1 \mathrm{M} \Omega$ in control saline and by $0.9 \mathrm{M} \Omega$ in the presence of $10 \mu \mathrm{m}$ picrotoxin. The effects of picrotoxin on GABA responses of four motor neurons and glutamate responscs of two motor neurons also were measured when the bath was superfused with high $\mathrm{Mg}^{2+}$-low $\mathrm{Ca}^{2+}$ saline; the results were the same as in normal saline (data not shown).

\section{Synaptic connections between motor neurons}

To measure synaptic connections between particular motor neurons, we recorded from pairs of neurons using intracellular microelectrodes and tested for direct interactions between them by injecting current into each one in turn. By digitizing the potentials of both neurons, we could accurately measure the amplitude and latency of any changes in the putative postsynaptic neuron.

A brief delay of the postsynaptic response is characteristic of a direct, monosynaptic connection. In earlier descriptions of monosynaptic connections between crayfish neurons including both electrical and chemical synapses, delays ranged from $<1$ to $\sim 3$ msec (Wine, 1977; Wiens and Atwood, 1978; Kennedy et al., 1980; Roberts et al., 1982; Kirk, 1985; Jones and Page, 1986a,b). Delays of polysynaptic connections, in contrast, ranged from 4 to $50 \mathrm{msec}$ (Kennedy et al., 1980; Jones and Page, 1986a,b; Takahata and Wine, 1987). These measurements were made with a microelectrode in the postsynaptic neuron and extracellular stimulation of a presynaptic axon, and therefore necessarily included some uncertainty about the time of arrival of the presynaptic spike at the synapse.

When it has been possible to measure these delays at central synapses in crayfish using microelectrodes in both the presynaptic and postsynaptic neurons, both excitatory and inhibitory synapses had delays of $0.7-1.3 \mathrm{msec}$. Some of these synapses were between sensory afferents and their targets (Nagayama and Sato, 1993; Newland and Nagayama, 1993)-excitatory synapses that would be predicted to be fast because they have an electrical component (Wine and Krasne, 1982); however, others were inhibitory synapses between interneurons that had no electrical component, but nonetheless had synaptic delays in this same range (Nagayama and Sato, 1993). In these same experiments, disynaptic pathways had delays of $>4 \mathrm{msec}$, the value predicted by summing the delays of two monosynaptic connections. Therefore, we interpreted delays of $<2 \mathrm{msec}$ to indicate monosynaptic connections, and delays of $>4 \mathrm{msec}$ to indicate polysynaptic connections. 
A Saline

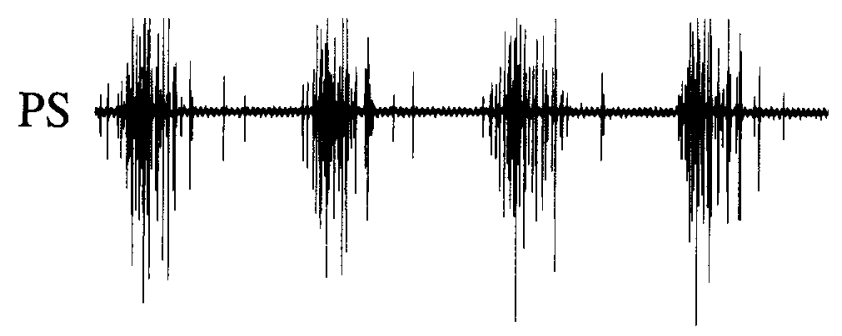

$1 \mu \mathrm{M}$ Picrotoxin

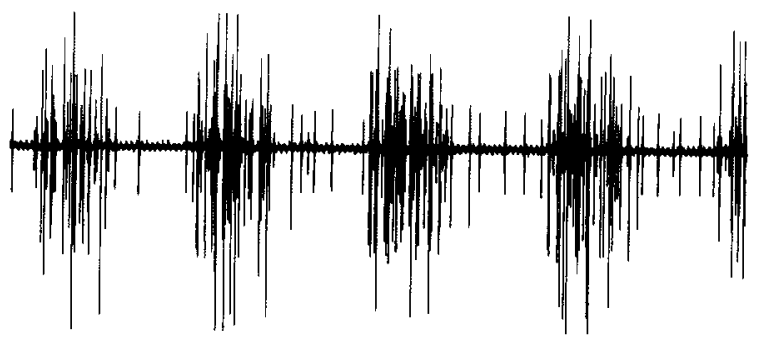

$1 \mathrm{~s}$.

B

Saline
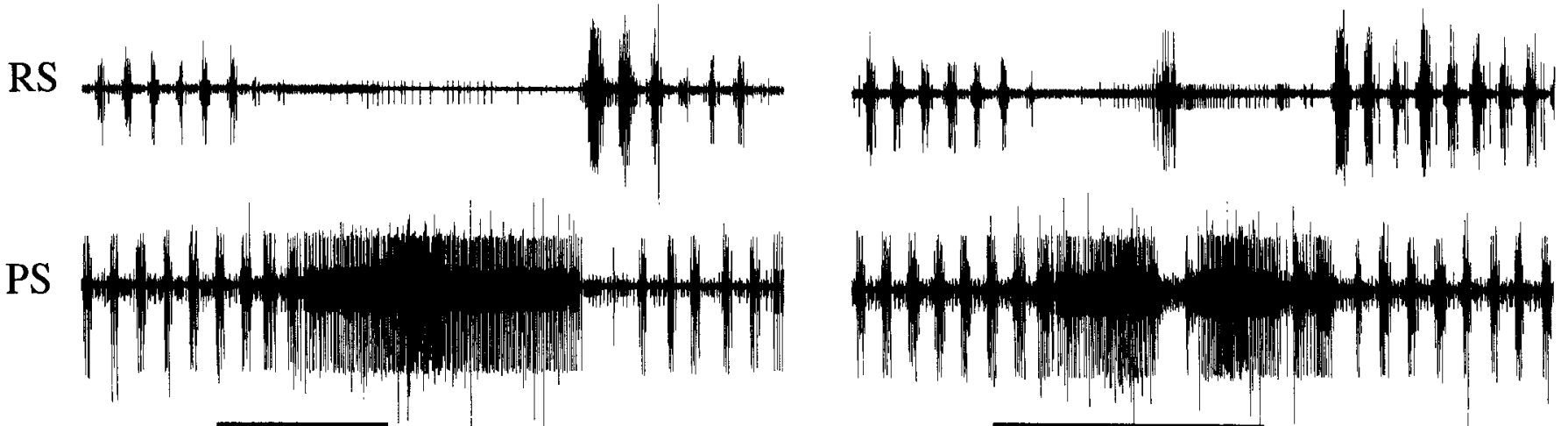

1 mM GABA

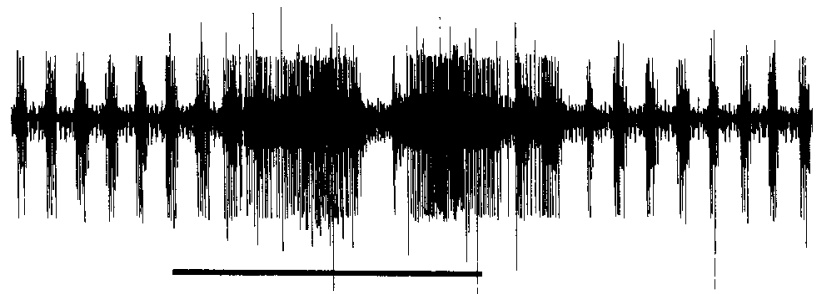

$1 \mathrm{mM}$ Glutamate

$4 \mathrm{~s}$.

\section{$1 \mu \mathrm{M}$ Picrotoxin}
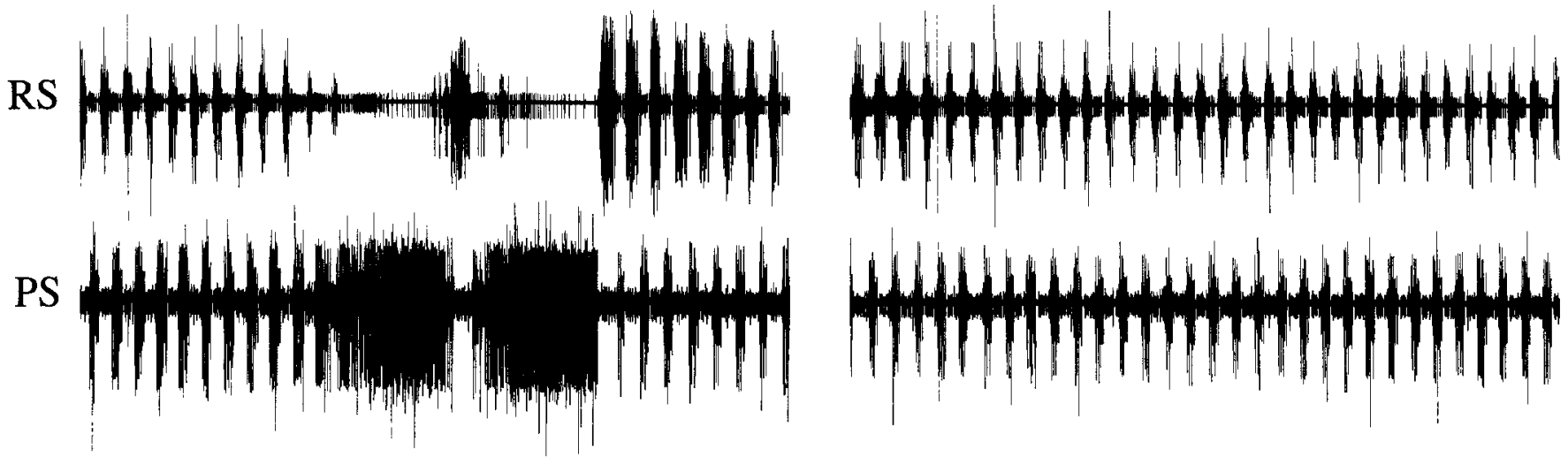

$1 \mathrm{mM}$ GABA

$1 \mathrm{mM}$ Glutamate

Figure 8. Picrotoxin increased firing activity in N1, blocked the glutamate response, but did not block the GABA response. $A$, Picrotoxin $(1 \mu \mathrm{M})$ increased the frequency of the motor pattern, increased the number of units firing in the motor pattern, and increased the firing frequency of units previously active in regular saline. These recordings (of bursts that occurred in $B$ and $C$ just before the GABA was applied) are expanded and enlarged to illustrate individual impulses. $B$, When the preparation was superfused with regular saline, both GABA and glutamate disrupted the swimmeret motor pattern by inhibiting bursts in both the RS and PS axons. $C$, When the nerve cord was superfused with saline plus $1 \mu \mathrm{M}$ picrotoxin, GABA still disrupted the motor pattern, but the glutamate response was abolished. 

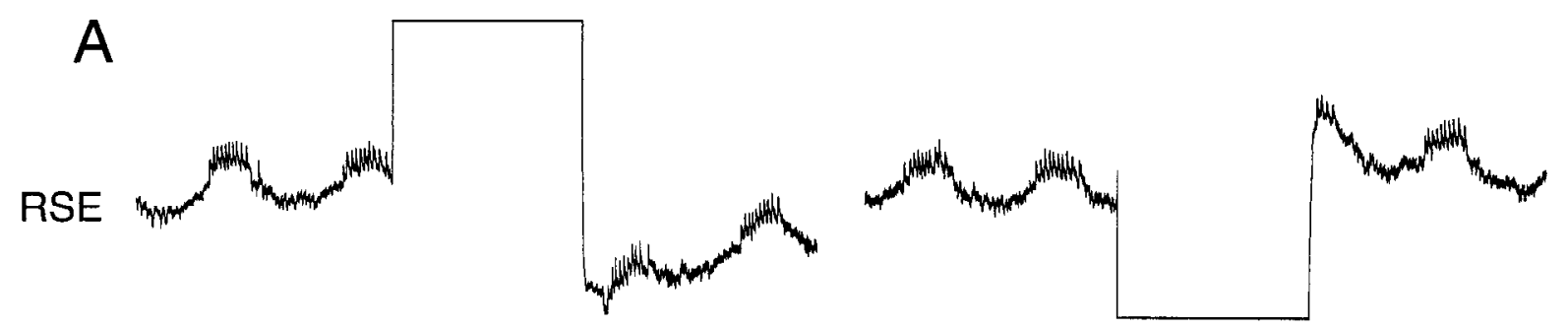

PSE
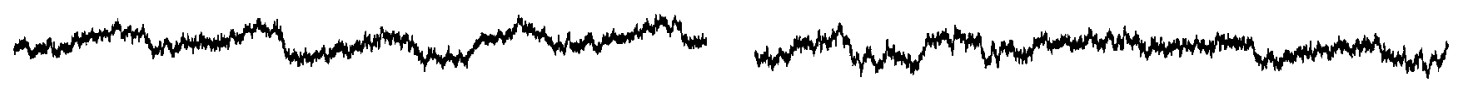

B
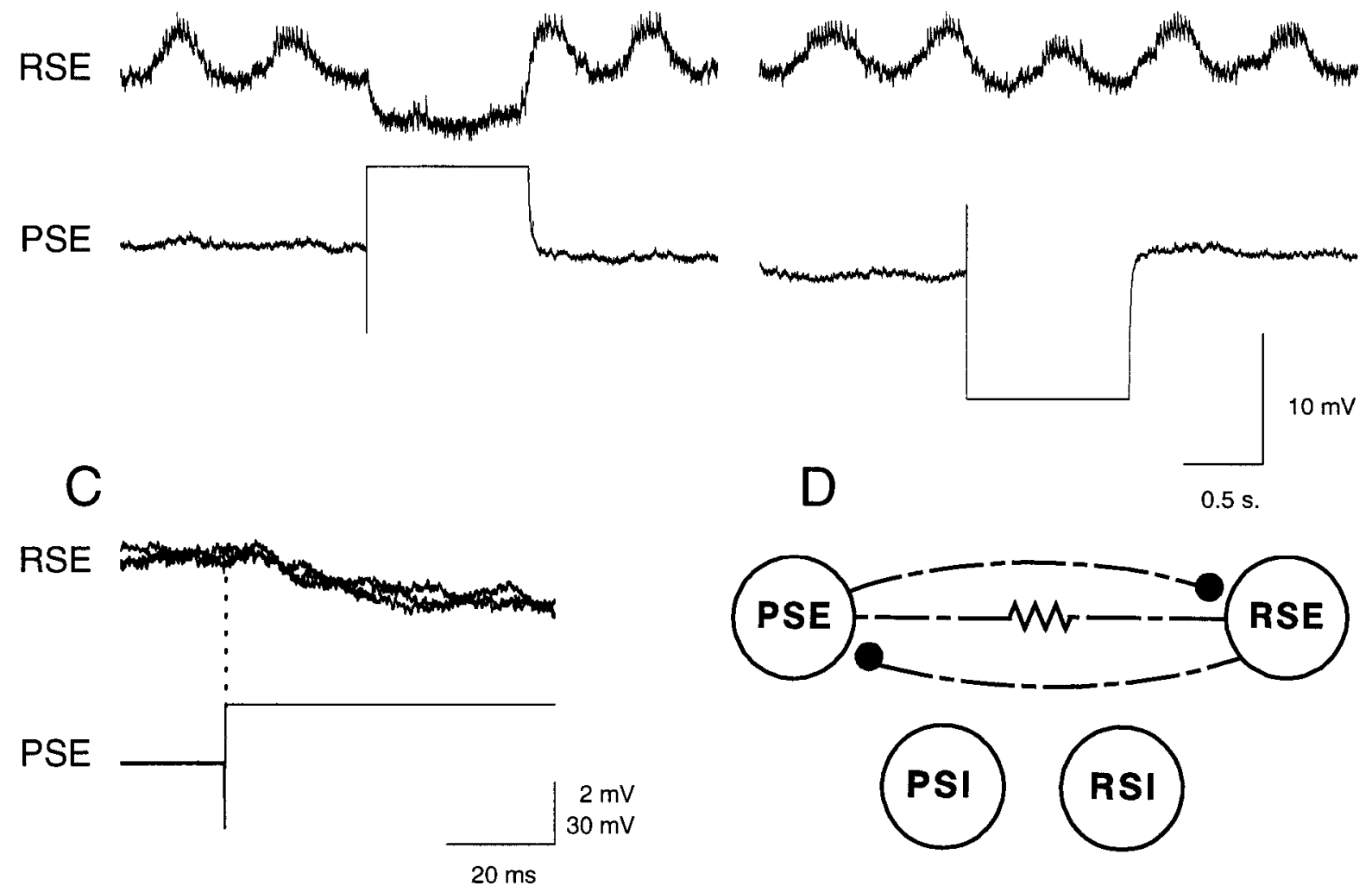

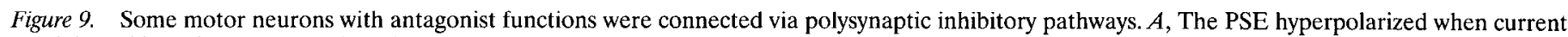

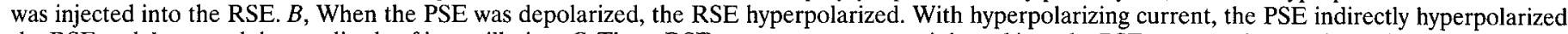

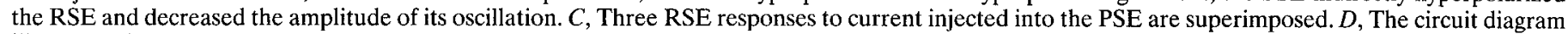

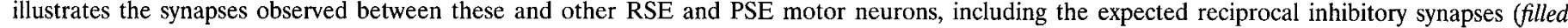

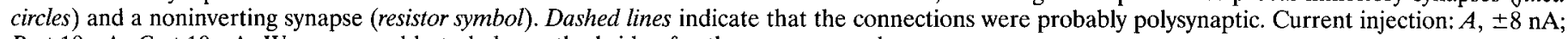
$B, \pm 10 \mathrm{nA} ; C,+10 \mathrm{nA}$. We were unable to balance the bridge for these current pulses.

\section{Antagonist motor neurons did not make monosynaptic connections}

In the swimmeret system, there are two different categories of antagonist interactions; those between motor neurons that excite antagonist muscles (PSE and RSE) and those between motor neurons that excite and inhibit the same muscles (PSE and PSI, or RSE and RSI). Motor neurons with antagonist functions are active in opposite phases of the motor pattern (Fig. 1), and connections between these neurons were predicted to be inhibitory (Fig. 2). In this study, we located 18 pairs of antagonist motor neurons and tested their interactions. Inhibitory connections were found in 8 of these 18 pairs. All of these connections appeared to be polysynaptic because their latencies were $>4 \mathrm{msec}$.

Evidence of synaptic connections were found in 5 of 13 PSE- 
RSE pairs (Table 5), indicating that synapses between antagonist excitors were not abundant. Inverting synapses were found in all five pairs, and their latencies were $>5 \mathrm{msec}$ (e.g., Fig. 9). Current injected into this RSE did not cause a sudden change in membrane potential of the PSE, but instead caused a gradual voltage change of the opposite polarity to that of the presynaptic cell (Fig. 9A). Hyperpolarization of the RSE also decreased the oscillation amplitude of the PSE (Fig. 9A). There was a stronger connection from the PSE to the RSE; depolarization of the PSE caused a discrete hyperpolarization of the RSE (Fig. 9B). This connection was also polysynaptic because although the latency was constant, it was $9 \mathrm{msec}$ long (Fig. 9C). Hyperpolarization of the PSE had a weak, polysynaptic effect on the RSE (Fig. 9B); the RSE was hyperpolarized and the amplitude of its oscillation dccrcascd.

The connections from the PSE to the RSE in Figure $9 B$ were especially interesting because they were contradictory. Both depolarization and hyperpolarization of the PSE resulted in hyperpolarization of the RSE (Table 5). We observed this noninverting response to hyperpolarization of a PSE only once in 13 PSE-RSE pairs, but it has been reported previously (Heitler, 1981), where it was interpreted as evidence of a direct electrical synapse (Fig. 2). Here, this connection appeared to be polysynaptic because the response of RSE was a decrease in the oscillation amplitude and a gradual hyperpolarization of the membrane potential that had no clear point of inflection from which to measure latency. This type of connection indicates that a simple model of monosynaptic inhibition between antagonists is a simplification of a more complex neural circuit.

We tested the connections between three pairs of RSE-RSI motor neurons and two pairs of PSE-PSI motor neurons. In each set, there was one pair that did not have any synaptic connections. In the others, we observed a combination of inverting and noninverting connections like the PSE-RSE pair described above (Table 5). Latencies of these connections ranged from 4 to 21 msec, which indicates that they were all polysynaptic. The two RSE-RSI pairs that synapsed with each other made indirect inhibitory connections that were not reciprocal (Fig. 10A). Depolarizing this RSE hyperpolarized the RSI with a latency of 6 msec. Hyperpolarizing this RSE indirectly decreased the RSI oscillation amplitude slightly (data not shown). Neither depolarizing (Fig. 10A) nor hyperpolarizing the RSI (not shown) had any effect on the RSE. The other RSE-RSI pair was similar; the RSE inhibited the RSI via a polysynaptic pathway.

The PSE-PSI pair that did interact also had an indirect, inhibitory connection, but from the inhibitor to the excitor. Its latency was $22 \mathrm{msec}$. As with the PSE-RSE pair in Figure 9A, these neurons also had a noninverting connection; hyperpolarizing the PSE caused a small but measurable hyperpolarization of the PSI (Fig. 10B). This hyperpolarization had a latency of $7 \mathrm{msec}$. There was no response either to depolarization of the PSE or to hyperpolarization of the PSI (data not shown).

\section{Synergist motor neurons from different groups did not make monosynaptic connections}

There are two different types of synergist motor neurons: those belonging to different groups (PSE-RSI or RSE-PSI) and those belonging to the same group (e.g., PSEs or RSEs). Synergists are active in the same phase of the motor pattern; therefore, one would predict that they would be electrically coupled to help coordinate their firing. Only 5 of the more than 70 swimmeret motor neurons in each hemiganglion are putative peripheral in- hibitors (Mulloney and Hall, 1990); therefore, recordings from them were uncommon. We did test the connections between one pair of synergists from different groups, a PSE-RSI pair. In contrast to antagonist motor neurons, each of these two neurons displayed noninverting responses to both depolarizing and hyperpolarizing current injected into the other (Fig. 11), although the coupling appeared to be extremely weak with depolarization of the PSE. This coupling was indirect; the shortest latency was 7 msec when hyperpolarizing current was injected into the PSE. More data are required before we can estimate the frequency of these connections and whether some of them might be monosynaptic.

\section{Motor neurons within the same functional group made direct electrical synapses}

Twelve of the 14 pairs from the same group (86\%) were coupled by weak, noninverting connections (PSE-PSE and RSE-RSE; Table 5). The latencies of these responses ranged from $<1$ to 17 msec. Six of 12 pairs were probably connected directly, because they had latencies $<2 \mathrm{msec}$, and these latencies were constant. One example of motor neurons that were probably directly coupled by nonrectifying gap junctions is shown in Figure 12. Depolarization or hyperpolarization of one PSE caused changes in membrane potential of the same polarity in the other cell, with short latencies.

To describe the relative strengths of these connections, coupling coefficients - the ratio of the postjunctional voltage response to a prejunctional voltage change-of connections between motor neuron pairs were calculated both for depolarizing and hyperpolarizing current injected into each neuron. Coupling coefficients were calculated for four pairs of synergists, in which bridge balance permitted accurate measurement of the change in presynaptic potential. Measured coupling coefficients ranged from 0.01 to 0.15 and had a mean of 0.06 (Table 5). For the other 10 pairs, coupling coefficients could not be measured because the amount of current required to produce a measurable postsynaptic response was too high to allow balancing of the bridge circuit. These pairs would have had coupling coefficients at or below the low end of the observed range.

In 8 of 12 pairs, including the 4 pairs with latencies $<1 \mathrm{msec}$, the connections were not rectifying. Three of the remaining four had characteristics of rectifying electrical synapses; positive current was carried across the junction in one direction, and negative current was carried only in the opposite direction. As in the crayfish motor giant-lateral giant synapse (Giaume and Korn, 1983), the $10-20 \mathrm{mV}$ difference measured between the resting membrane potentials of the neurons in these three pairs might be a factor in the observed rectification.

The latencies and coupling coefficients are shown for a typical pair of motor neurons (Fig. 13), the same pair shown in Figure 12. These were probably direct, electrical synapses. Response latencies to depolarizing (Fig. 13A,B) or hyperpolarizing (not shown) current injected into either neuron were $<1 \mathrm{msec}$. The coupling coefficients were 0.04 and 0.06 with $+2 \mathrm{nA}$ and $-3 \mathrm{nA}$ injected into PSE 1 (Fig. 13C), and 0.15 with $+3 \mathrm{nA}$ injected into PSE 2 (Fig. 13D). The amount of current that was required to hyperpolarize PSE 2 sufficiently to cause a response in PSE 1 was too large for us to balance the bridge, so we were unable to measure this coupling coefficient.

In two PSE-PSE pairs, one or both motor neurons could reset the swimmeret motor pattern when current pulses were injected into them. Although these neurons would be the ones most likely 


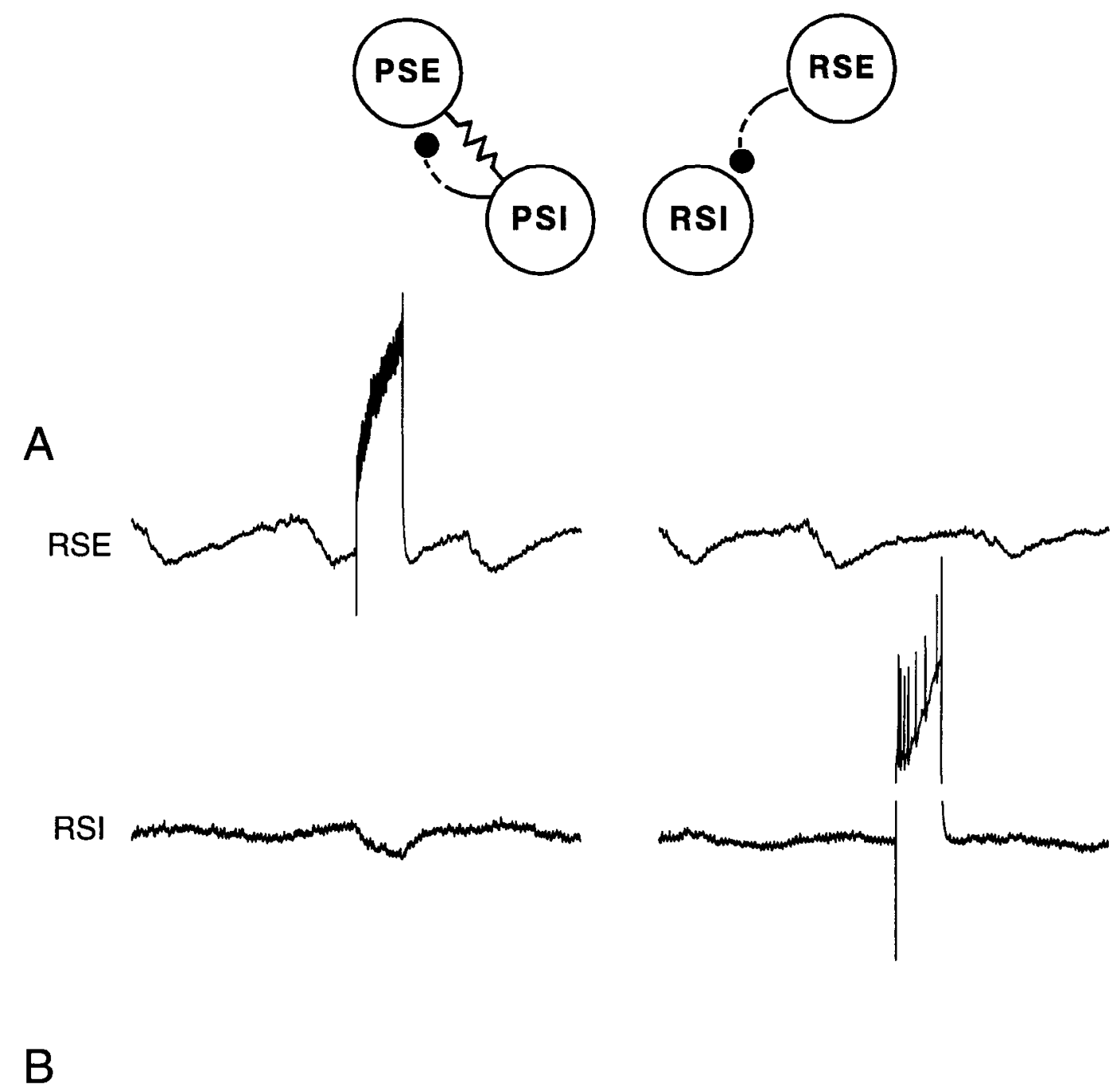

PSE
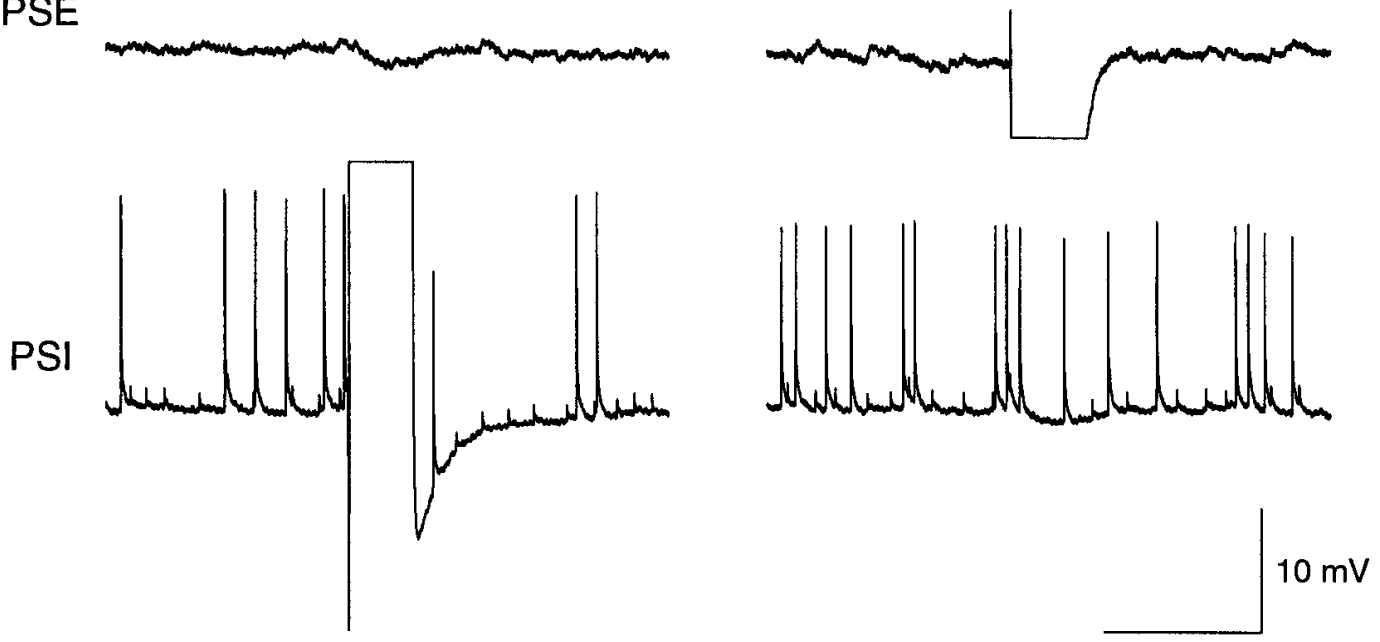

$0.5 \mathrm{~s}$.

Figure 10. Connections between excitor motor neurons and inhibitor motor neurons of the same muscles were polysynaptic and usually inhibitory. The circuit diagram shows the synapses observed between these two pairs of excitor and inhibitor antagonists (PSE-PSI and RSE-RSI). The connection represented by the dashed line and resistor symbol indicated a noninverting, polysynaptic connection. $A$, In this RSE-RSI pair, depolarizing the RSE hyperpolarized the RSI. $B$, In this PSE-PSI pair, depolarizing the PSI led to a hyperpolarization of the PSE, and hyperpolarizing the PSE caused a hyperpolarization of the PSI. Current injection: $A,+8,+6 \mathrm{nA} ; B,+8,-9 \mathrm{nA}$. The electrode could not be balanced for the hyperpolarizing current pulse in $B$, and the record has been truncated. 

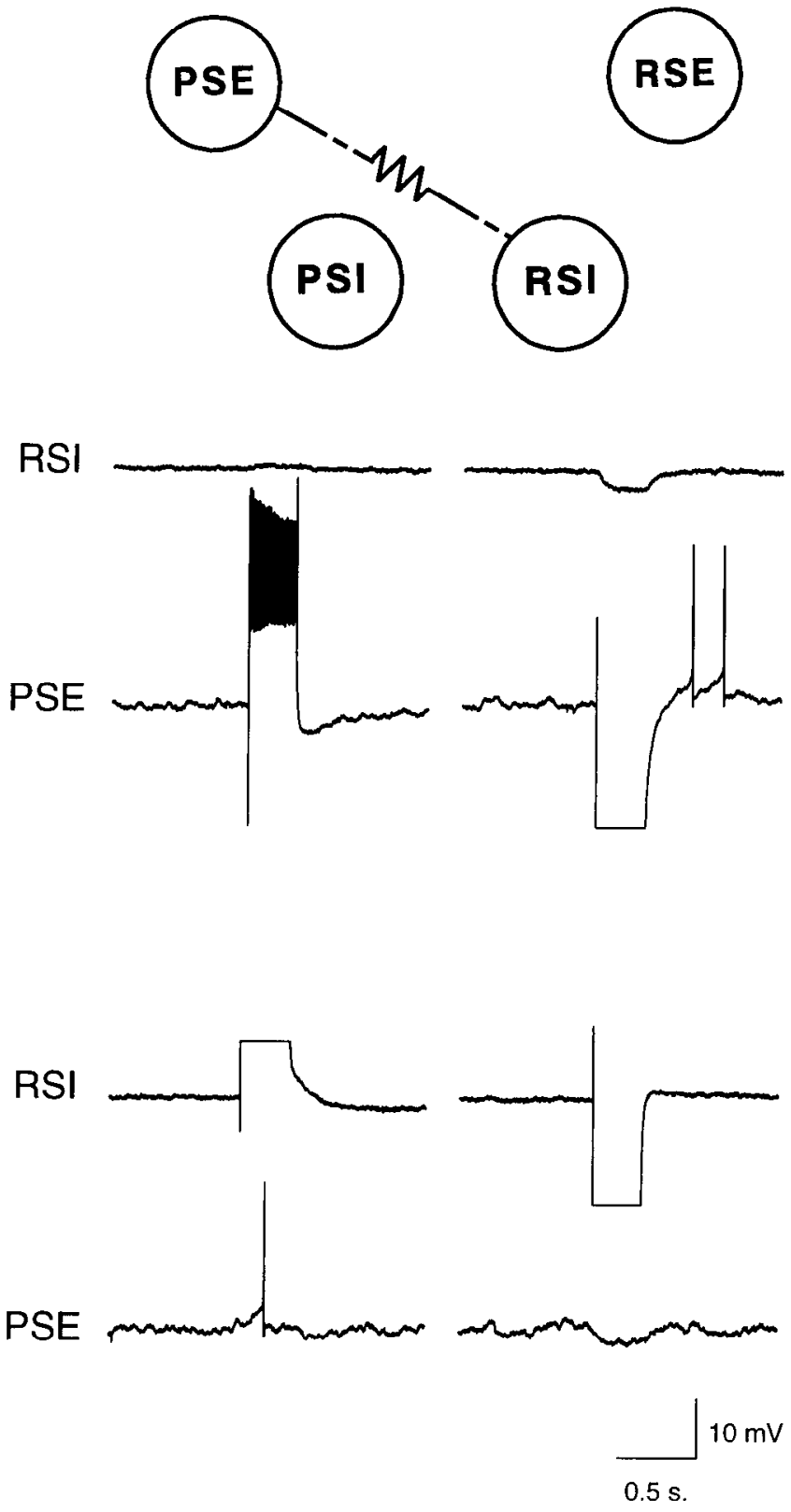

Figure 11. Some synergist motor neurons from different functional groups were connected by a noninverting, polysynaptic pathway. Current injection of either polarity into the PSE (top) or the RSI (bottom) caused a response of the same polarity in the other motor neuron. The latencies of these responses were $>7 \mathrm{msec}$.

to be members of the pattern-generating circuits, the connection between the two resetting motor neurons and the connection between a resetting motor neuron and a nonresetting motor neuron were polysynaptic.

\section{Dye coupling between motor neurons}

In the physiological experiments, only two motor neurons could be studied at one time. To estimate the numbers of neurons electrically coupled to a given motor neuron, we injected Neurobiotin into one motor neuron and counted how many others were dye-coupled to it. Each filled motor neuron was classified physiologically, as in earlier experiments. Neurobiotin was ionophor- esed into single motor neurons $(n=22)$ for as long as $2.25 \mathrm{hr}$ to allow the tracer to diffuse throughout the cell and through gap junctions into other cells. Neurobiotin was visualized with Cy3Streptavidin, and the population of fluorescent cells was counted. The neuron that had been directly filled could be recognized as the brightest cell in the whole-mount, because it contained the highest concentration of Neurobiotin. The number of cells dyecoupled to swimmeret motor neurons ranged from 1 to 53 , with a mean of 13.

One PSE motor neuron was filled in each ganglion shown in Figure 14. The first features to notice about these two preparations are differences in the numbers and locations of neurons filled. In Figure 14A, only the impaled motor neuron was labeled; it was not dye-coupled to any other neurons. Only 3 of the 22 motor neurons filled showed this complete lack of dyc coupling. In contrast, the PSE filled in Figure $14 B$ was dye-coupled to 33 other neurons. These two examples indicate the range of dye coupling seen in these 22 cells.

In addition to being dye-coupled to different numbers of cells, motor neurons within a group showed different patterns of dye coupling (Fig. 15). The four ganglia with filled RS motor neurons in this figure had between $7(A)$ and $53(D)$ dye-coupled neurons. The filled neurons of ganglia $A, B$, and $C$ were coupled only to cells that had ipsilateral cell bodies. The filled neuron in $D$ was coupled to 6 contralateral neurons, in addition to 45 ipsilateral neurons.

The filled motor neuron in Figure $15 A$ was weakly coupled to the six other labeled neurons. In Figure $15, B-D$, there were a few cells that appeared more strongly dye-coupled than the rest. In Figure $15 B$, two RS motor neurons were both brightly labeled. These two had very similar shapes and locations. Their cell bodies were adjacent to one another, and their primary neurites twisted around each other, as did their proximate axons. The other labeled cells in this ganglion were only weakly dye-coupled. They appeared only as dim cell bodies; no processes were visible.

A similar pattern is observed in Figure $15 \mathrm{C}$. Once again, two closely apposed neurons were tightly dye-coupled, and their processes followed one another. Here, however, three other cell bodies were also strongly coupled to the filled motor neuron. Their somata, primary neurites; and some of their neuropil processes were brightly labeled, although because of the thickness of the tissue, the primary neurite is visible for only one of these cells in the plane of focus of this photograph. Three of the brightly labeled neurons were identified as motor neurons because they had labeled axons that could be traced to N1 (Fig. 15E).

The RS motor neuron filled in Figure $15 D$ showed a different shape and a very different pattern of coupling than did the others. It was coupled to 46 anterior and posterior cells, whereas the motor neurons in Fig. $15 A-C$ were coupled mostly to other anterior neurons. This motor neuron was also dyecoupled to six contralateral neurons, whereas in the other preparations, the motor neurons were coupled only to ipsilateral motor neurons. This cell was strongly coupled to another anterior cell body, to a posterior cell body, and to its contralateral homolog. The contralateral processes of the two homologs could be seen crossing the midline. Most of the other dye-filled neurons were only weakly dye-coupled to the filled motor neuron.

Although up to 53 neurons were dye-coupled, no more than three filled axons were ever seen in N1 (Fig. 15E). Many of the 

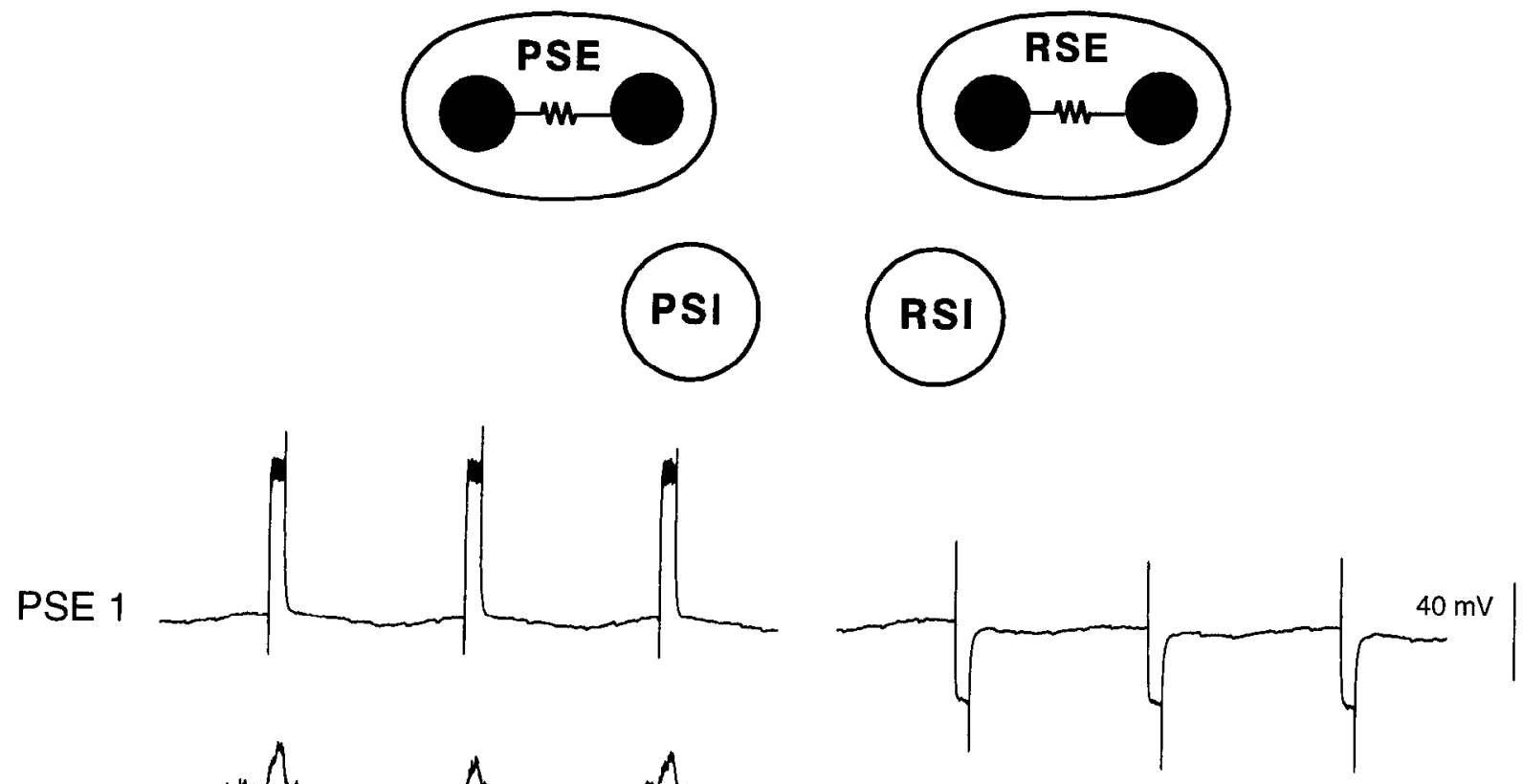

PSE 2
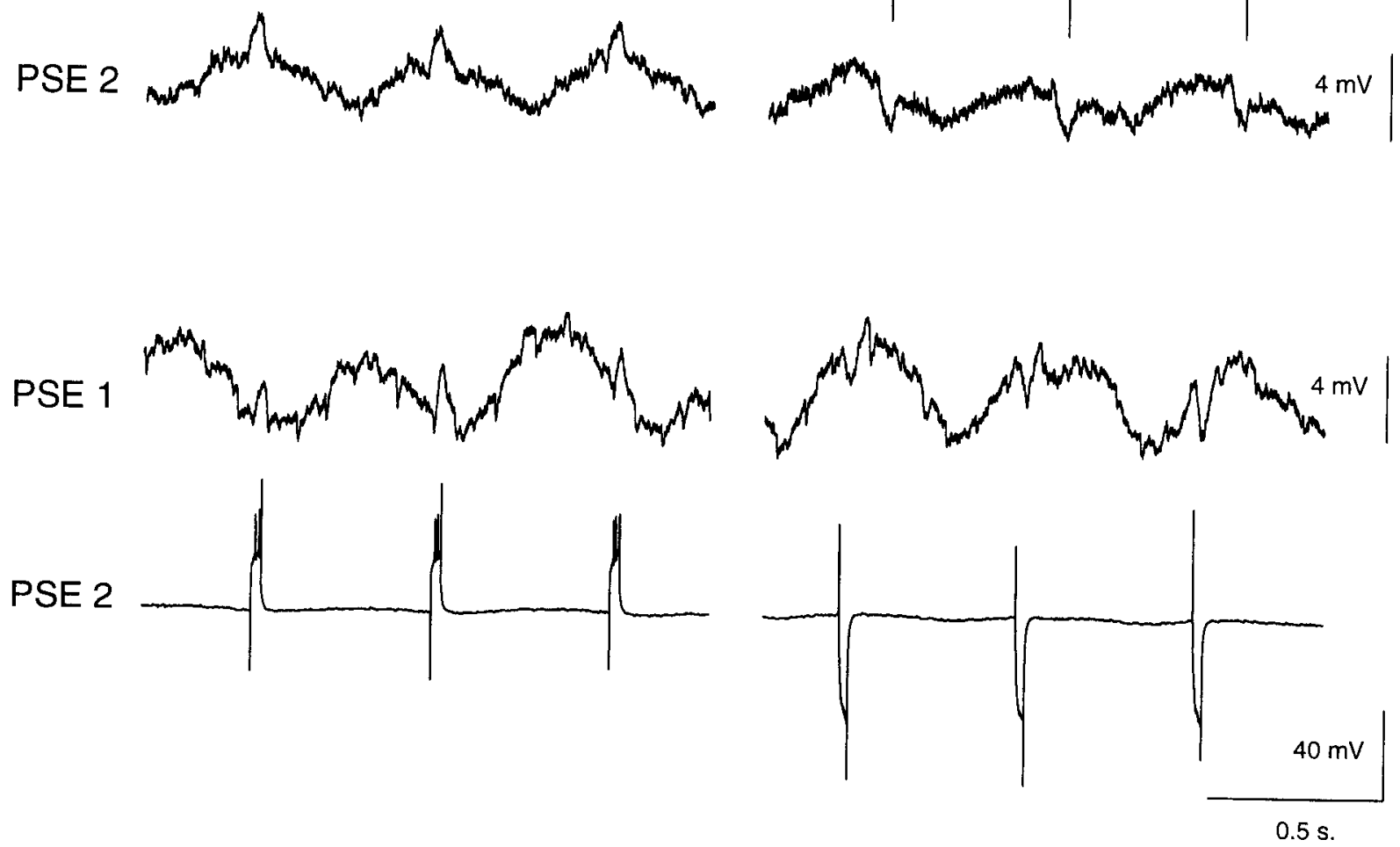

Figure 12. Motor neurons of the same functional group were directly coupled by nonrectifying gap junctions. Microelectrode recordings in the figure are from a pair of PSEs. Current $( \pm 6 \mathrm{nA})$ injected into either of these two motor neurons caused a noninverting response in the other, with latencies $<1$ msec.

dye-coupled cells that could not be identified anatomically as motor neurnns were probably interneurons. Paul previously identified more than 30 local and intersegmental interneurons (Paul and Mulloney, 1985a,b, 1986), at least 15 of which have cell body locations similar to the motor neurons. One of these interneurons is interneuron 1A (IN1A), which is electrically coupled to an RS motor neuron. This interneuron was labeled in Figure 15D. Thus, the number of direct dye coupling connections between motor neurons was probably substantially smaller than these data indicate.

\section{DISCUSSION}

The motor neuron model (Fig. 2) of the pattern-generating circuit has been influential because it summarized effectively a large body of experimental findings, but it has not been tested critically. In these experiments, we tested both physiological and pharmacological predictions of this model: that swimmeret motor neurons would be inhibited both by GABA and by glutamate, that they would make monosynaptic inhibitory connections with their functional antagonists, that they would be electrically coupled to their functional synergists, and that 
A

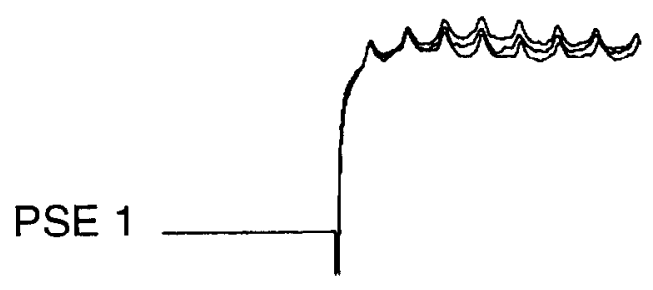

PSE 2

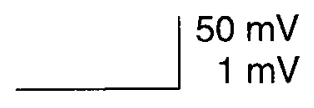

$10 \mathrm{~ms}$

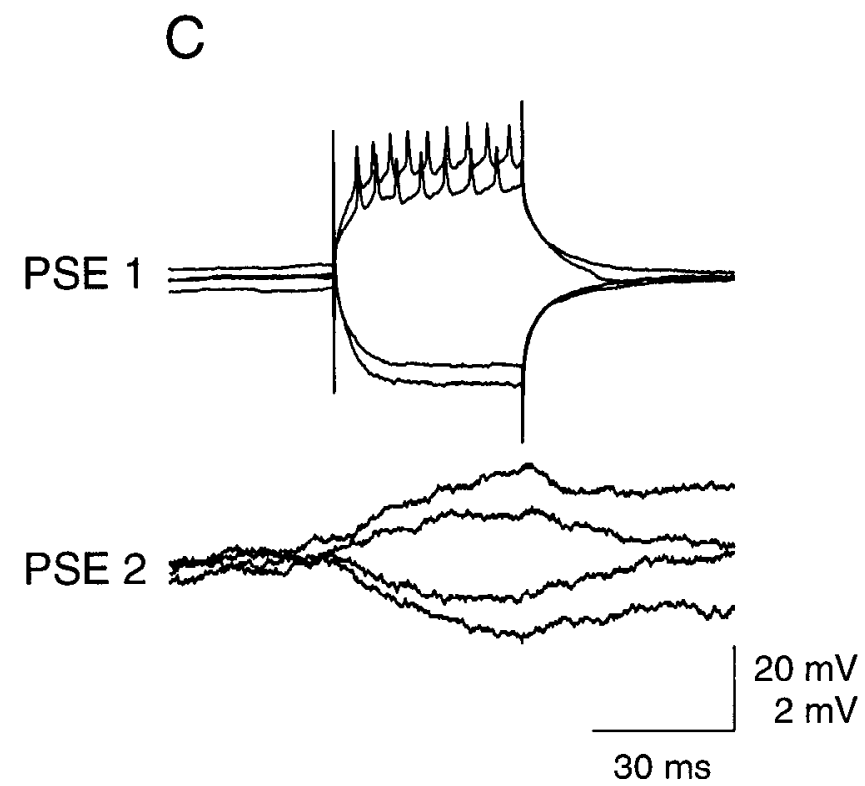

B

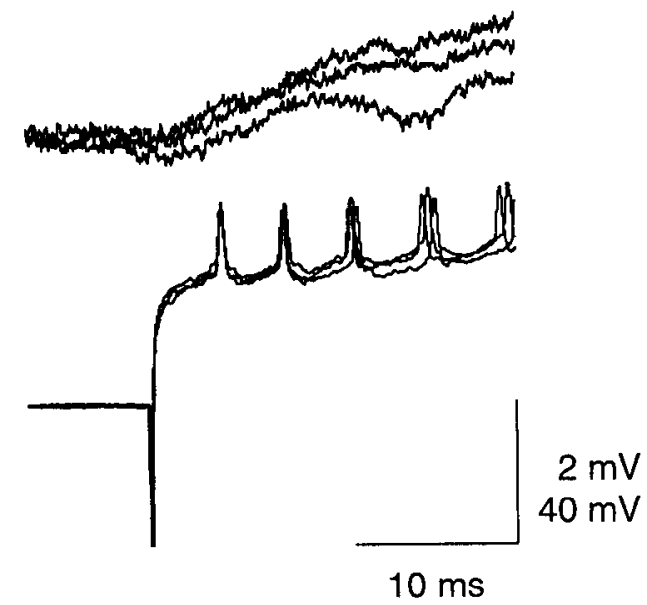

D

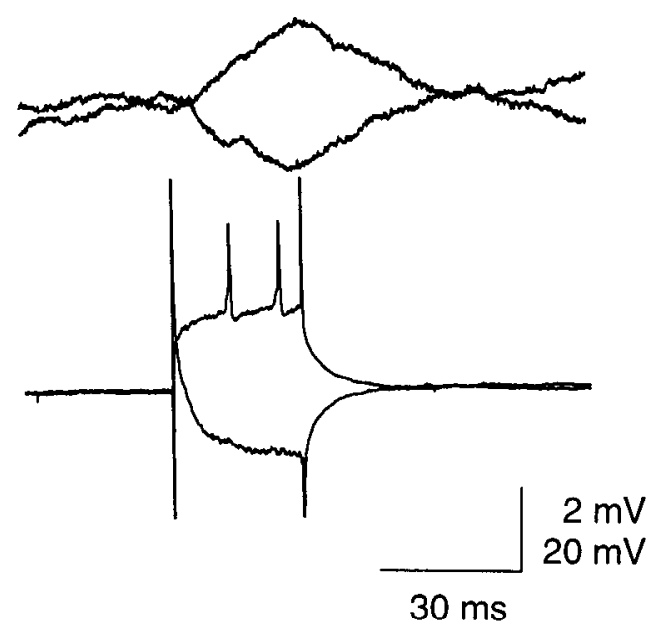

Figure 13. Latencies and coupling coefficients of a typical electric synapse between motor neurons of the same functional group. $A, B$, Latencies of the postsynaptic responses to injection of $+9 \mathrm{nA}$ into PSE $1(A)$ and PSE $2(B)$ were $<1 \mathrm{msec}$, indicating that these were direct electrical synapses. $C$, $D$, Coupling coefficients from PSE 1 to PSE 2 were 0.06 for depolarizing current and 0.04 for hyperpolarizing current. From PSE 2 to PSE 1 , the coupling coefficient was 0.15 with depolarizing current. In $A$ and $B$, all records are single traces. In $C$ and $D$, presynaptic records are single traces to show spikes, whereas postsynaptic records are averages of seven traces.

these synapses would be strong. The neurotransmitter responses of swimmeret motor neurons and their networks of electrical synapses are consistent with the model, but the physiology of synaptic connections between functional groups of motor neurons contradicts it.

\section{Both GABA and glutamate inhibited the motor pattern}

In the motor-neuron model (Fig. 2), both excitatory glutamatergic motor neurons and inhibitory GABAergic motor neurons make inhibitory synapses directly with other swimmeret motor neurons that innervate the same swimmeret. Because we expect these neurons to release the same transmitters at both their peripheral and central synapses, the model predicts that each type of swimmeret motor neuron will be inhibited by direct application of these transmitters to its processes in the neuropil. Our results show that both neurotransmitters inhibited expression of the swimmeret motor pattern on the side of the ganglion into which they had been injected (Fig. 4), and that one site of this inhibition was the swimmeret motor neurons themselves (Fig. 5). These results are not surprising for GABA, which is usually associated with an inhibitory function, but inhibitory glutamate responses are not common. A few other examples of inhibitory glutamate action in crustaceans are known, including stomatogastric motor neurons (Marder and Paupardin-Tritsch, 1978; Cleland and Selverston, 1995), and the axon terminals (Miwa and Kawai, 1986; Miwa et 

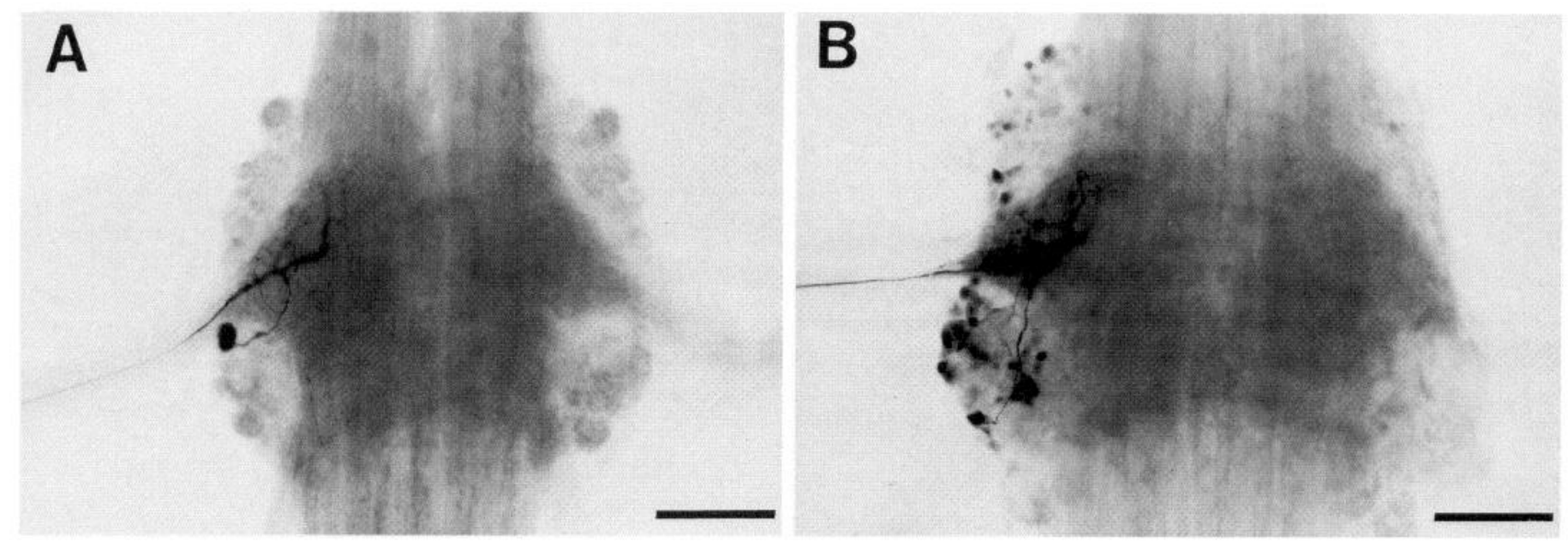

Figure 14. Different swimmeret motor neurons, even within the same functional group, varied in the numbers of other neurons to which they were dye-coupled. In each of these two preparations, a PSE motor neuron was filled with Neurobiotin and labeled with Cy3-Streptavidin. The PSE in $A$ was not dye-coupled to any other neurons, whereas the PSE in $B$ was dye-coupled to 33 other neurons. Scale bars, $200 \mu \mathrm{m}$.

al., 1990) and central processes (Pearlstein et al., 1994) of lobsters and crayfish walking-leg motor neurons.

\section{Both GABA and glutamate inhibited swimmeret motor neurons by gating $\mathrm{Cl}^{-}$channels}

These transmitters might inhibit motor neurons by gating either $\mathrm{Cl}^{-}$or $\mathrm{K}^{+}$channels. Opening either type of channel would cause both inhibition and conductance increases, but the $E_{\mathrm{R}}$ of the resulting IPSPs would differ significantly. $E_{\mathrm{K}}$ is approximately $-100 \mathrm{mV}$ at the presynaptic terminals of the leg motor axon in lobster (Miwa and Kawai, 1986; Miwa et al., 1990), considerably more negative than the $-65 \mathrm{mV} \mathrm{E}_{\mathrm{Cl}}$ in other crustacean cells, including motor neurons of the crayfish leg (Pearlstein et al., 1994). The combination of the measured $E_{\mathrm{R}}$ (Table 2; Fig. 6) and the pharmacology of these responses indicates that the dominant effect of both GABA and glutamate is the gating of $\mathrm{Cl}^{-}$conductances. We recorded similar GABA and glutamate responses in both excitatory and inhibitory motor neurons; these responses did not differ with the peripheral function of the neurons.

Picrotoxin, which blocks some $\mathrm{Cl}^{-}$channels, decreased or blocked the ability of glutamate to inhibit expression of the swimmeret motor pattern, but did not affect GABA's inhibition (Fig. 8). These two neurotransmitters might bind to receptors associated with two different populations of $\mathrm{Cl}^{-}$channels that have different picrotoxin sensitivity. Many $\mathrm{Cl}^{-}$channels are sensitive to picrotoxin, but other examples of picrotoxin-insensitive $\mathrm{Cl}^{-}$channels associated with GABA receptors have been reported. Although it is not conventional for glutamate-gated channels to be blocked by picrotoxin, picrotoxin does block some glutamate responses; an extrajunctional glutamate-gated conductance on locust muscle is blocked by picrotoxin (Cull-Candy, 1976), and both $\mathrm{Cl}^{-}$and $\mathrm{K}^{+}$-sensitive glutamate responses of stomatogastric neurons in the crab (Marder and PaupardinTritsch, 1978) and lobster (Cleland and Selverston, 1995) are blocked by picrotoxin. Although picrotoxin blocked or decreased the effects of glutamate on the motor pattern, it decreased the glutamate response of only one of four motor neurons recorded. This heterogeneity might result from differences among motor neurons in the expression of receptors, or might result from local clustering of different receptors on different regions of each motor neuron (e.g., Parker, 1994).
The inhibitory effects of GABA on swimmeret motor neurons were mimicked by muscimol (Fig. 7). Muscimol is in many cases an effective agonist of $\mathrm{GABA}_{\mathrm{A}}$ receptors, even those that are insensitive to bicuculline (Olsen et al., 1976). The insensitivity of the GABA response to bicuculline indicates that the GABA receptors that are present on the central processes of these motor neurons are not conventional $\mathrm{GABA}_{\mathrm{A}}$ receptors (Ishida, 1992). The insensitivity of swimmeret motor neurons and the swimmeret system both to baclofen and to CACA, agonists of the $\mathrm{GABA}_{\mathrm{B}}$ and $\mathrm{GABA}_{\mathrm{C}}$ receptors, indicates that neither of these receptors plays a significant role here.

\section{Some synergist motor neurons made direct electrical synapses}

Approximately half of the pairs of motor neurons in the same functional group or in synergist groups were connected by noninverting, nonrectifying synapses (Table 5). These synapses were not strong; their coupling coefficients were $<0.15$. Within a group, some pairs appeared to be directly coupled; dye coupling between two or three motor neurons was often observed (Figs. 14, 15). These dye-coupled sets might be motor neurons that innervate the same muscle in the swimmeret.

Many of the postsynaptic responses of these synergists had latencies $<2 \mathrm{msec}$. The $>1 \mathrm{msec}$ difference between the slowest monosynaptic connection we observed and the fastest polysynaptic connection we observed is both well within the accuracy of our methods and equal to the additional delay of the disynaptic connection demonstrated by Nagayama and Sato [(1993), their Fig. 6]. These weak electrical synapses confirm the earlier description of electrical coupling of synergists (Heitler, 1978, 1981) and are consistent with the motor-neuron model.

\section{Antagonist motor neurons did not make monosynaptic connections}

Less than half of the pairs of antagonist motor neurons that we tested were connected (Table 5). The most common connections between pairs of antagonist motor neurons were inhibitory, just as the motor-neuron model predicted. However, many of these were not reciprocal, and all the measured latencies of these connections were $>4 \mathrm{msec}$, much longer than the $<2$ msec latencies of the monosynaptic connections be- 

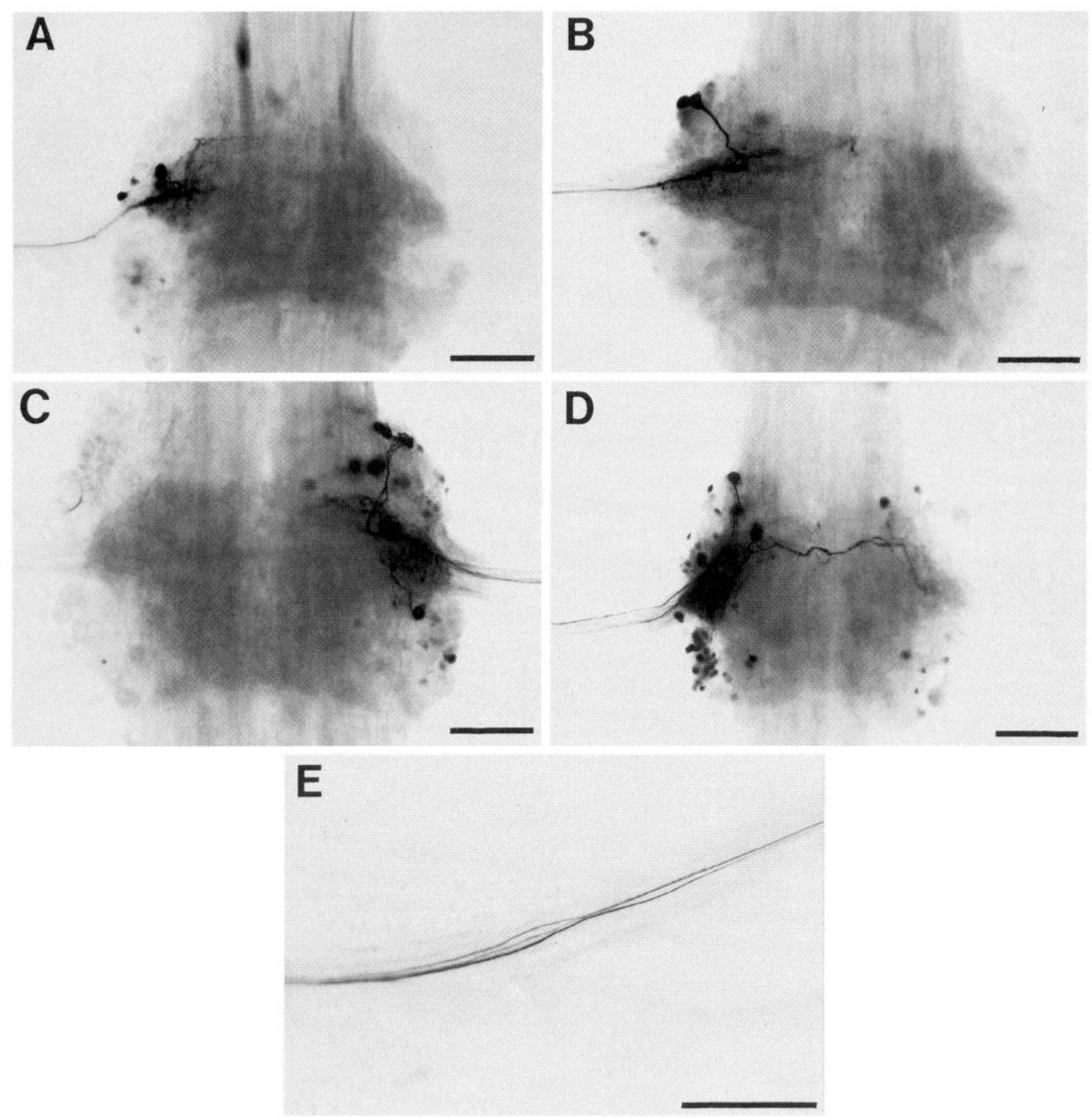

Figure 15. $A-D$, Neurobiotin fills of four different RS motor neurons. The patterns of dye coupling in these four preparations differed in the numbers and locations of dye-coupled cells. Some of the coupled neurons could be identified as motor neurons by the presence of labeled axons in N1. Part of the right $\mathrm{N} 1$ from $C$ is shown in $E$; three labeled axons are visible. Scale bars, $200 \mu \mathrm{m}$.

tween motor neurons in the same group (above), or in earlier measurements of latencies between other crayfish motor neurons (Wiens and Atwood, 1978; Nagayama and Sato, 1993). Therefore, contrary to the prediction of the motor-neuron model, these connections were not monosynaptic. Either direct inhibition between antagonist groups of motor neurons is accomplished by only a few special motor neurons (by chance, none of these was encountered in these experiments) or inhibition occurs via polysynaptic pathways.

We found noninverting connections in two PSE-PSI pairs and one PSE-RSE pair of antagonists. These connections appeared to be polysynaptic. Coupling between RSE and PSE motor neurons was first documented by Heitler (1981), who suggested that this was an electrical synapse. However, in our 
experiments, all of the noninverting connections between motor neuron groups appeared to be polysynaptic; the RSE-PSE noninverting connection we measured had a latency $>5 \mathrm{msec}$ (Fig. 3).

\section{The role of synapses between motor neurons in generating the swimmeret motor pattern}

The weakness of synapses between motor neurons contradicts the hypothesis that these synapses are significant components of the local swimmeret pattern-generating circuitry. Although some motor neurons are capable of resetting the swimmeret motor pattern, the resetting neurons from which we recorded made polysynaptic connections with other motor neurons. Furthermore, these connections were no stronger than those between nonresetting motor neurons. We think the resetting motor neurons exert their effects on the motor pattern via polysynaptic pathways that involve unilateral nonspiking local interneurons (Paul and Mulloney, 1985a,b), which may be the major components of the patterngenerating circuit. These local interneurons affect firing in many motor neurons, and require much less current to produce these responses than the motor neurons require to generate their much weaker effects. The abundance of polysynaptic connections between motor neurons supports the importance of interneurons for the production of alternation bursts of RS and PS action potentials.

The original demonstration that currents injected into some swimmeret motor neurons could reset the entire swimmeret rhythm (Heitler, 1978) raised the possibility that strong synapses between motor neurons, like those already known in the stomatogastric circuitry (Mulloney, 1987), might be characteristic of crustacean motor systems. The systems that generate swimming in leeches, another segmented phylum, also have demonstrable synaptic connections between motor neurons within each segment (Friesen, 1989a), but these connections make a minor contribution to the motor pattern that drives swimming, relative to the segmental interneurons (Friesen, 1989b). Synaptic connections between motor neurons that participate in walking (Burrows, 1992; Ryckebusch and Laurent, 1993) or flight (Robertson, 1990) have been sought but not observed. Spinal motor neurons of frogs are coupled by weak electrical synapses (Collins, 1983), but careful study of spinal mechanisms that drive swimming in fish have not found evidence that interactions between motor neurons play a role (Wallén and Lansner, 1984; Grillner et al., 1995). Thus, although previously it seemed possible that segmental motor systems in crustaceans had different organizational principles than their equivalents in annelids, insects, and vertebrates, the results reported here make this possibility unlikely; except for the weak electrical synapses between motor neurons that innervate the same muscles, connections between swimmeret motor neurons are polysynaptic

\section{REFERENCES}

Bennett MVL (1977) Electrical transmission: a functional analysis and comparison to chemical transmission. In: Handbook of physiology, Sec 1, The nervous system (Kandel ER, ed), pp 357-416. Bethesda, MD: American Physiological Society.

Braun G, Mulloney B (1995) Coordination in the crayfish swinneret system: differential excitation causes changes in intersegmental phase. J Neurophysiol 73:880-885.

Burrows M (1992) Local circuits for the control of leg movements in an insect. Trends Neurosci 15:226-232.

Cleland TA, Selverston AI (1995) Glutamate-gated inhibitory currents of central pattern generator neurons in the lobster stomatogastric ganglion. J Neurosci 15:6631-6639.
Collins WF, III (1983) Organization of electrical coupling between frog lumbar motor neurons. J Neurophysiol 49:730-744.

Cull-Candy SG (1976) Two types of extrajunctional alpha-glutamate receptors in locust muscle fibers. J Physiol (Lond) 255:449-464.

Davis WJ (1969) Neural control of swimmeret beating in the lobster. J Exp Biol 50:99-117.

Davis WJ (1971) Functional significance of motoneuron size and soma position in swimmeret system of the lobster. J Neurophysiol 34:274-288.

Dekin MS (1983) Permeability changes induced by L-glutamate at the crayfish neuromuscular junction. J Physiol (Lond) 341:105-125.

Dudel J, Gryder R, Kaji A, Kuffler SW, Potter DD (1963) Gammaaminobutyric acid and other blocking compounds in crustacea. I. Central nervous system. J Neurophysiol 26:721-728.

Dudel J, Franke C, Hatt H (1990) Rapid activation, desensitization, and resensitization of synaptic channels of crayfish muscle after glutamate pulses. Biophys $\mathbf{J}$ 57:533-545.

El Manira $\Lambda$, Clarac F (1994) Presynaptic inhibition is mediated by histamine and GABA in the crustacean escape reaction. J Neurophysiol 71:1088-1095.

Feigenspan A, Wassle H, Bormann J (1993) Pharmacology of GABA receptor $\mathrm{Cl}^{-}$channels in rat retinal bipolar cells. Nature 361:159-162.

Friesen WO (1989a) Neuronal control of leech swimming movements. I. Inhibitory interactions between motor neurons. J Comp Physiol [A] 166:195-203

Friesen WO (1989b) Neuronal control of leech swimming movements. II. Motor neuron feedback to oscillator cells 115 and 28. J Comp Physiol [A] 166:205-215.

Fuchs PA, Getting PA (1980) Ionic basis of presynaptic inhibitory potentials at crayfish claw opener. J Neurophysiol 43:1547-1557.

Giaume C, Korn H (1983) Bidirectional transmission at the rectifying electrotonic synapse: a voltage-dependent process. Science 220:84-87.

Grillner S, Deliagina T, Ekeberg Ö, El Manira A, Hill RH, Lansner A Orlovsky GN, Wallén P (1995) Neural networks that co-ordinate locomotion and body orientation in lamprey. 'Irends Neurosci 18:270-279.

Heitler WJ (1978) Coupled motoneurones are part of the crayfish swimmeret central oscillator. Nature 275:231-234.

Heitler WJ (1981) Neural mechanisms of central pattern generation in the crayfish swimmeret system. In: Advances in physiological science, Vol 23, Neurobiology of invertebrates (Salanki J, ed), pp 369-383. Oxford: Pergamon.

Heitler WJ (1982) Non-spiking stretch receptors in the crayfish swimmerct systcm. J Exp Biol 96:355-366.

Heitler WJ (1983) The control of rhythmic limb movements in crustacea. Symp Soc Exp Biol 37:351-382.

Heitler WJ, Darrig S (1986) The segmental giant neurone of the signal crayfish, Pacifastacus leniusculus, and its interactions with abdominal fast flexor and swimmeret motoneurones. J Exp Biol 121:55-75.

Heitler WJ, Mulloney B (1978) Crayfish motorneurons are an integral part of the swimmeret central oscillator. Soc Neurosci Abstr 4:211.

Heitler WJ, Pearson KG (1980) Non-spiking interactions and local interneurones in the central pattern generator of the crayfish swimmeret system. Brain Res 187:206-211.

Ishida AT (1992) The physiology of $\mathrm{GABA}_{\mathrm{A}}$ receptors in retinal neu rons. Prog Brain Res 90:29-45.

Jones KA, Page CH (1986a) Postural interneurons in the abdominal nervous system of lobster. II. Evidence for neurons having both command and driver roles. J Comp Physiol [A] 158:273-280.

Jones KA, Page CH (1986b) Postural interncurons in the abdominal nervous system of lobster. III. Pathways mediating intersegmental spread of excitation. J Comp Physiol [A] 158:281-290.

Kaila K, Rydqvist B, Pasternack M, Voipio J (1992) Inward current caused by sodium-dependent uptake of GABA in the crayfish stretch receptor neurone. J Physiol (Lond) 453:627-645.

Kennedy D, McVittie J, Calabrese R, Fricke RA, Craelius W, Chiapella P (1980) Inhibition of mechanosensory interneurons in the crayfish. I. Presynaptic inhibition from giant fibers. J Neurophysiol 43:1495-1509.

Kerrison J, Freschi JE (1992) The effects of gamma-aminobutyric acid on voltage-clamped motoneurons of the lobster cardiac ganglion. Comp Biochem Physiol 101C:227-233.

Kirk MD (1985) Presynaptic inhibition in the crayfish CNS: pathways and synaptic mechanisms. J Neurophysiol 54:1305-1325.

Kravitz EA, Kuffler SW, Potter DD, van Gelder NM (1963a) Gammaaminobutyric acid and other blocking compounds in crustacea. II. Peripheral nervous system. J Neurophysiol 26:729-738. 
Kravitz EA, Kuffler SW, Potter DD (1963b) Gamma-aminobutyric acid and other blocking compounds in crustacea. III. Their relative concentrations in separated motor and inhibitory axons. J Neurophysiol 26:739-751.

Lea TJ, Usherwood PNR (1973) Effect of ibotenic acid on chloride permeability of insect muscle fibers. Comp Gen Pharmacol 4:351-363.

Lingle C, Marder E (1981) A glutamate-activated chloride conductance on a crustacean muscle. Brain Res 212:481-488.

Marder E, Paupardin-I'ritsch D (1978) The pharmacological properties of some crustacean neuronal acetylcholine, gamma-aminobutyric acid and L-glutamate responses. J Physiol (Lond) 280:213-236.

McDonald VN (1981) Central effects of motor neurons on swimmeret motor output. Master's thesis, University of California, Davis.

Miwa A, Kawai N (1986) Presynaptic glutamate receptor-possible involvement of a $\mathrm{K}^{+}$channel. Brain Res 385:161-164.

Miwa A, Ui M, Kawai N (1990) G protein is coupled to presynaptic glutamate and GABA receptors in lobster neuromuscular synapse. J Neurophysiol 63:173-180.

Mulloney B (1987) Neural circuits. In: The crustacean stomatogastric system (Selverston AI, Moulins M, eds), pp 57-75. Berlin; Springer

Mulloney B, Hall WM (1990) GABAergic neurons in the crayfish nervous system: an immunocytochemical census of the segmental ganglia and stomatogastric system. J Comp Neurol 291:383-394.

Mulloney B, Acevedo LD, Bradbury AG (1987) Modulation of the crayfish swimmeret rhythm by octopamine and the neuropeptide proctolin. J Neurophysiol 58:584-597.

Mulloney B, Acevedo LD, Chrachri A, Hall WM, Sherff CM (1990) A confederation of neural circuits: control of swimmeret movements by a modular system of pattern generators. In: Frontiers in crustacean neurobiology (Wiese K, Krenz WD, Tautz J, Reichert H, Mulloney B, eds), pp 439-447. Basel: Birkhauser.

Mulloney B, Murchison D, Chrachri A (1993) Modular organization of pattern-generating circuits in a segmental motor system: the swimmerets of crayfish. Semin Neurosci 5:49-57.

Murchison D, Chrachri A, Mulloney B (1993) A separate local patterngenerating circuit controls the movements of each swimmeret in crayfish. J Neurophysiol 70:2620-2631.

Nagayama T, Sato M (1993) The organization of exteroceptive information from the uropod to ascending interneurones of the crayfish. J Comp Physiol [A] 172:281-294.

Newland PL, Nagayama T (1993) Parallel processing of proprioceptive information in the terminal abdominal ganglion of the crayfish. J Comp Physiol [A] 172:389-400.

Olsen RW, Ban M, Miller T (1976) Studies on the neuropharmacological activity of bicuculline and related compounds. Brain Res 102:283-299.

Onodera K, Takeuchi A (1975) Ionic mechanism of the excitatory synaptic membrane of the crayfish neuromuscular junction. J Physiol (Lond) 252:295-318.

Onodera K, Takeuchi A (1976) Permeability changes produced by L-glutamate at the excitatory post-synaptic membrane of the crayfish muscle. J Physiol (Lond) 255:669-686.
Parker D (1994) Glutamatergic transmission between antagonistic motor neurones in the locust. J Comp Physiol [A] 175:737-748.

Paul DH, Mulloncy B (1985a) Local interneurons in the swimmeret system of the crayfish. J Comp Physiol [A] 156:489-502.

Paul DH, Mulloney B (1985b) Nonspiking local interneuron in the motor pattern generator for the crayfish swimmeret. J Neurophysiol 54:28-39.

Paul DH, Mulloney B (1986) Intersegmental coordination of swimmeret rhythms in isolated nerve cords of crayfish. J Comp Physiol [A] 158:215-224.

Pearlstein E, Marchand AR, Clarac F (1994) Inhibitory effects of L-glutamate on central processes of crustacean leg motoneurons. Eur J Neurosci 6:1445-1452.

Qian H, Dowling JE (1993) Novel GABA responses from rod-driven retinal horizontal cells. Nature 361:162-164.

Roberts A, Krasne FB, Hagiwara G, Wine JJ, Kramer AP (1982) Segmental giant: evidence for a driver neuron interposed between command and motor neurons in the crayfish escape system. J Neurophysiol 47:761-781.

Robertson RM (1990) Synchronous activity of flight neurons in the mesothoracic ganglion of the locust. J Comp Physiol [A] 167:61-69.

Ryckebusch S, Laurent G (1993) Rhythmic patterns evoked in locust leg motor neurons by the muscarinic agonist pilocarpine. J Neurophysiol 69:1583-1595.

Skinner K (1985) The structure of the fourth abdominal ganglion of the crayfish, Procambarus clarkii. II. Synaptic neuropils. J Comp Neurol 234:182-191.

Stein PSG (1971) Intersegmental coordination of swimmeret motor neuron activity in crayfish. J Neurophysiol 34:310-318.

Takahata M, Winc JJ (1987) Feedforward afferent excitation of peripheral inhibitors in the crayfish escape system. J Neurophysiol 58:1452-1467.

Takeuchi A, Takeuchi N (1964) The effect on crayfish muscle of iontophoretically applied glutamate. J Physiol (Lond) 170:296-317.

Takeuchi A, Takeuchi N (1965) Localized action of GABA on the crayfish muscle. J Physiol (Lond) 177:225-238.

Van Harreveld A (1936) A physiological solution for freshwater crustaceans. Proc Soc Exp Biol Med 34:428-432.

Wallén P, Lansner A (1984) Do the motoneurones constitute a part of the spinal network generating the swimming rhythm in the lamprey? J Exp Biol 113:493-497.

Wiens TJ, Atwood HL (1978) Motoneuron interaction in crayfish claw control: evidence from intracellular recording. J Comp Physiol [A] $124: 237-247$

Wine JJ (1977) Neuronal organization of crayfish escape behavior: inhibition of giant motoneuron via a disynaptic pathway from other motoneurons. J Neurophysiol 40:1078-1097.

Wine JJ, Krasine FB (1982) The cellular organization of crayfish escape behavior. In: The biology of crustacea, Vol 4, Neural integration and behavior (Sandeman DC, Atwood HL, eds), pp 241-292. New York: Academic. 